2015-02-01

\title{
A review of combined wave and offshore wind energy
}

\author{
Perez Collazo, Carlos
}

http://hdl.handle.net/10026.1/4547

10.1016/j.rser.2014.09.032

Renewable and Sustainable Energy Reviews

Elsevier

All content in PEARL is protected by copyright law. Author manuscripts are made available in accordance with publisher policies. Please cite only the published version using the details provided on the item record or document. In the absence of an open licence (e.g. Creative Commons), permissions for further reuse of content should be sought from the publisher or author. 


\title{
A review of combined wave and offshore wind energy
}

\author{
C. Pérez-Collazo ${ }^{\mathrm{A}}$, D. Greaves ${ }^{\mathrm{A}}$, G. Iglesias ${ }^{\mathrm{A}}$ \\ ${ }^{\text {A }}$ School of Marine Science and Engineering, University of Plymouth, Marine Building, Drake Circus, Plymouth, PL4 \\ 8AA, UK \\ * Corresponding author \\ Email: carlos.perezcollazo@plymouth.ac.uk
}

\begin{abstract}
:
The sustainable development of the offshore wind and wave energy sectors requires optimising the exploitation of the resources, and it is in relation to this and the shared challenge for both industries to reduce their costs that the option of integrating offshore wind and wave energy arose during the past decade. The relevant aspects of this integration are addressed in this work: the synergies between offshore wind and wave energy, the different options for combining wave and offshore wind energy, and the technological aspects. Because of the novelty of combined wave and offshore wind systems, a comprehensive classification was lacking. This is presented in this work based on the degree of integration between the technologies, and the type of substructure. This classification forms the basis for the review of the different concepts. This review is complemented with specific sections on the state of the art of two particularly challenging aspects, namely the substructures and the wave energy conversion.
\end{abstract}

Keywords: Marine renewable energy; Combined wave and wind energy; Hybrids; Wave energy; Offshore wind; Review 


\section{Contents}

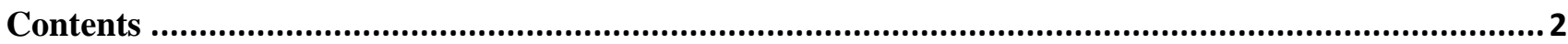

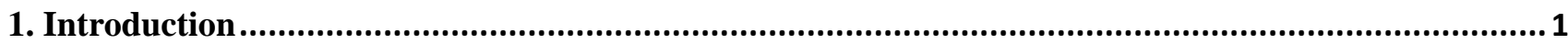

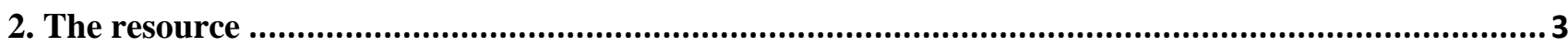

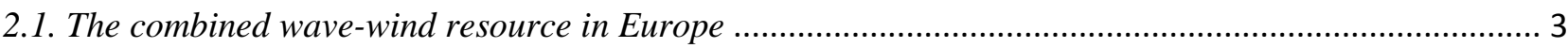

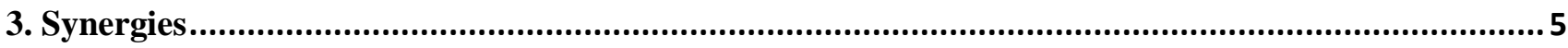

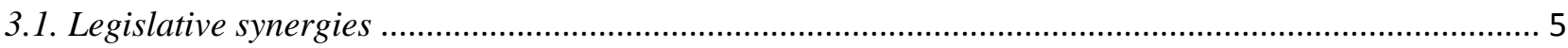

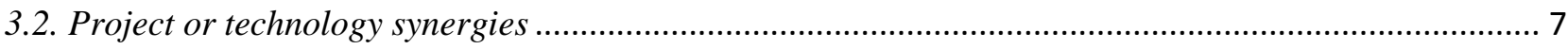

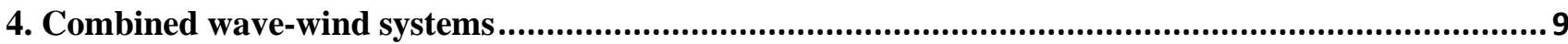

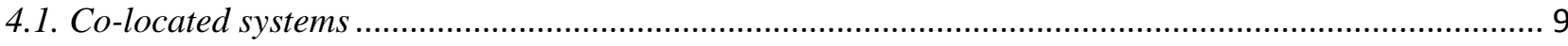

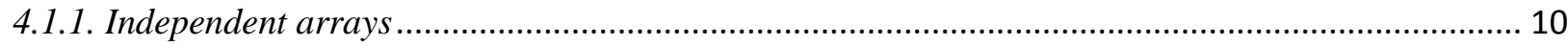

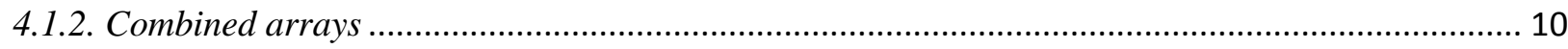

4.2. Hybrid systems

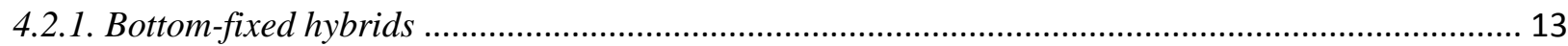

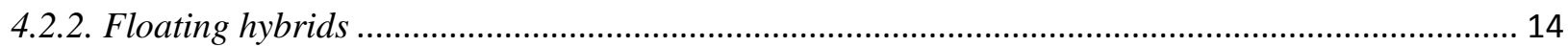

4.3. Island systems

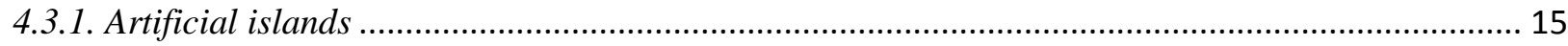

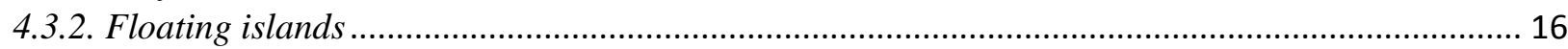

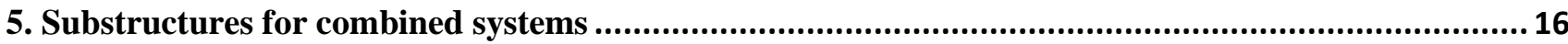

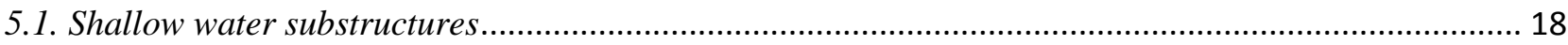

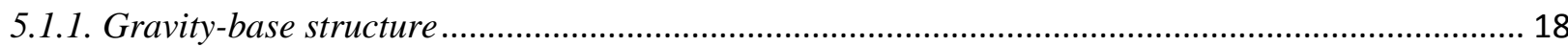

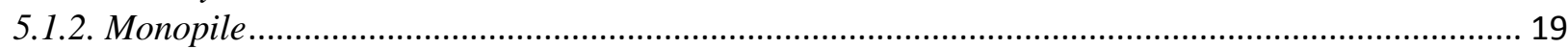

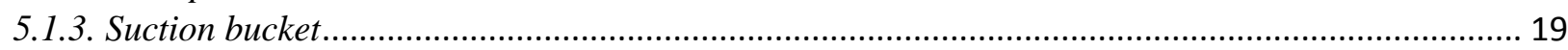

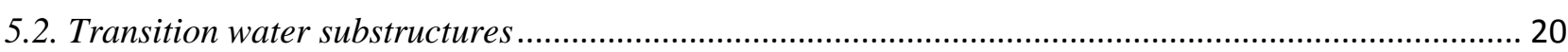

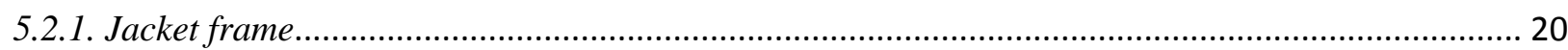

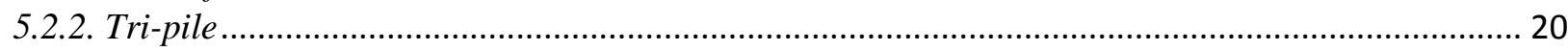

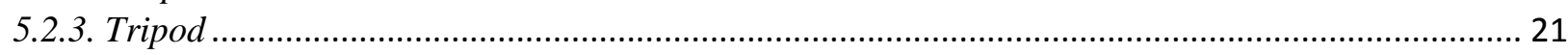

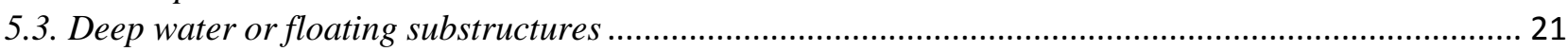

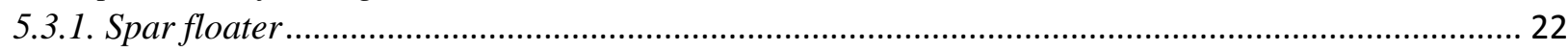

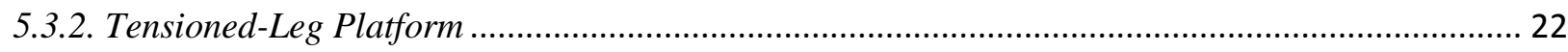

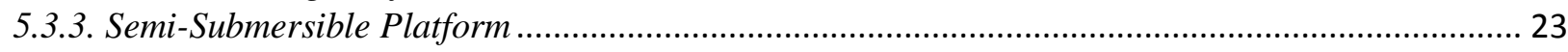

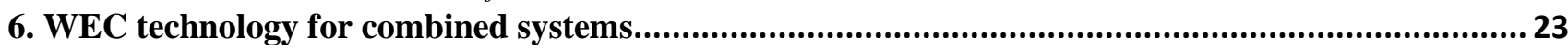

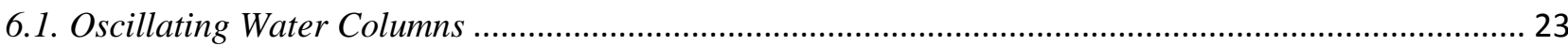

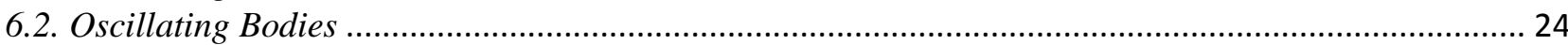

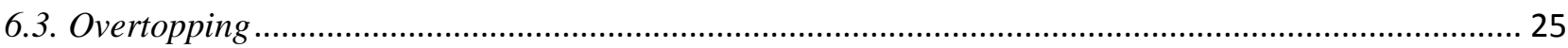

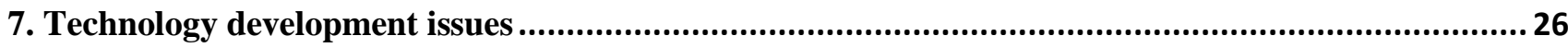

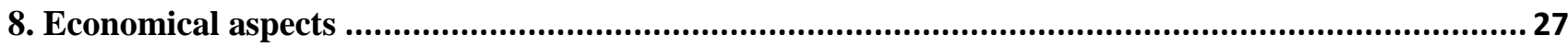

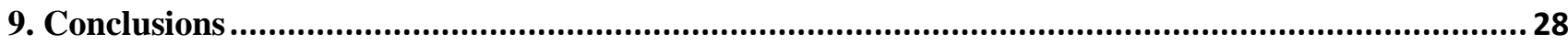

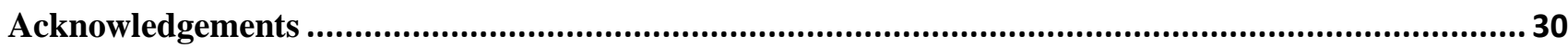

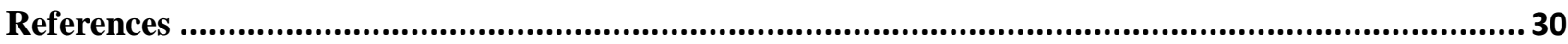

Figure captions .................................................................................... Error! Bookmark not defined.

Abbreviations: GBS, Gravity Based Substructures; MRE, Marine Renewable Energy; NDA, Non-

uniformly distributed Array; O\&M, Operation and Maintenance; ORE, Offshore Renewable Energy;

PDA, Peripherally Distributed Array; SET-Plan, Strategic Energy technology Plan; TRL,

Technology Readiness Level; UDA, Uniformly Distributed Array. 


\section{Introduction}

Offshore Renewable Energy (ORE), which includes both ocean energy and offshore wind, has a great potential for development $[1,2]$ and is called to play a fundamental role in the EU energy policy, as identified by, e.g., the European Strategic Energy Technology Plan (SET-Plan). The industry has established, as a target for 2050, an installed capacity of $188 \mathrm{GW}$ and $460 \mathrm{GW}$ for ocean energy (wave and tidal) and offshore wind, respectively [3-5]. Given that the target for 2020 is 3.6 GW and $40 \mathrm{GW}$, respectively [6], it is clear that a very substantial increase must be achieved if the 2050 target is to be realised, in particular in the case of ocean energy.

Offshore wind energy is defined as the energy generated from the wind at sea, and ocean energy as the energy present in oceans and other water bodies in the form of: waves, marine currents, tides, ocean thermal energy gradients or salinity gradients. Sharing the same hostile marine environment, ORE industries face similar challenges, yet their level of technological development is not the same. Whereas offshore wind is a proven technology, with $3.8 \mathrm{GW}$ of installed capacity in Europe and employing 35,000 people directly and indirectly at the end of $2011[5,7]$, ocean energies are still at an early stage of development.

The sustainable development of offshore wind and ocean energy requires an efficient use of the natural resources, i.e., one that optimises their exploitation. It is in relation to this and the challenge, common to both industries, to reduce costs that the incentive for integration arises. Within ocean energy this review is restricted to wave energy, for the other ocean energy technologies either are at present less developed either the combined resource is scarce and hence present fewer opportunities for integration with offshore wind.

The combined exploitation of wave and offshore wind energies is a very recent research topic, a limited number of papers draw on the combination of wave and offshore wind energy being these mostly focused on the resource assessment and potential of a combined wave-wind energy extraction [8-12] or the grid integration issues of a combined electric production [13, 14]. Some seminal 
publications which are mainly focused on either the combined electricity production (from the point of view of grid management) [15-21], either the proposal of new alternatives to combine the exploitation of wave-wind energies (i.e. energy islands or hybrid wave-wind energy converters) [2226] or looking into the different synergies between both energies and its implications [27]. Nevertheless, most of the work carried on in the last few years on combined wave-wind energy has been done by some EU funded research projects [28-32] which try to enhance the industrial and scientific collaboration to develop a more sustainable energy. As an output of these projects some research or public reports have tackled the combination of wave and offshore wind energy [4, 3335], focusing on the combined resource, the synergies between different OREs and the technical requirements of a hybrid platform. Apart from these specific studies, there have not been any publications that present a general view of the different combined wave and offshore wind possibilities, including those making use of the bottom-fixed offshore wind technology which is currently of commercial interest $[36,37]$.

The objective of the present paper is to review the different alternatives for combining wave and offshore wind energy, to give a complete view of the possibilities and current limitations of these systems. It is structured as follows: In Section 2 the combined wave-wind resource is analysed, with special attention to the European possibilities. Section 3 outlines the synergies between both energies. The various options are classified and examined in Section 4. The two main aspects from the technological point of view, the substructures and the wave energy conversion technologies, are reviewed in Sections 5 and 6, respectively. Section 7 looks into the technology development issues which of combined wave-wind systems. The economics of combined systems is outlined in Section 8. Finally, conclusions are drawn in Section 9. 


\section{The resource}

OREs, and especially offshore wind and waves, are amongst the renewables with the greatest potential. In the European coasts the available energy power is about: $350 \mathrm{GW}$ for wind and $320 \mathrm{GW}$ for waves (considering the NE Atlantic and Mediterranean). This represents the 50\% for Wind, 46\% waves and the remaining $4 \%$ for tidal $[1,3,4]$. Nevertheless, is at the North Atlantic costs and at the North Sea, where Europe's has its strongest and more valuable wind and wave energy resources.

The best wave conditions for exploitation as an energy resource are found in medium-high latitudes and on deep waters (more than $40 \mathrm{~m}$ ), reaching power densities of $60-70 \mathrm{~kW} / \mathrm{m}$. Moreover, about $2 \%$ of the world's $800,000 \mathrm{~km}$ of coastline exceed a power density of $30 \mathrm{~kW} / \mathrm{m}$, with a technical potential of about $500 \mathrm{GWe}$ based on a conversion efficiency of $40 \%$. The total European wave energy resources are estimated to be $1,000 \mathrm{TWh} / \mathrm{yr}$ while globally wave energy can produce 2,000-4,000 TWh/yr. In the European north-eastern Atlantic (including the North Sea), the available wave energy power resource is about $290 \mathrm{GW}$ and for the Mediterranean $30 \mathrm{GW}[1,4]$.

Like with waves, most windy areas are normally found in medium-high latitudes, however the wind resource is highly affected by local atmospheric effects. This means that normally the offshore wind resource is present at the west coastal areas of the northern hemisphere countries and at the east coastal areas on the southern hemisphere. Europe has strong offshore wind energy potential at the shallow waters of the North Sea, proven by the development of this industry during recent years at this basin. Furthermore, the deep waters of the European Atlantic coast, where the strongest potential of European waters is present, give the right conditions for the development of the next generation of floating wind turbines.

\subsection{The combined wave-wind resource in Europe}

The EU FP7 Co-ordinated action project ORECCA [29] analysed the ORE combined resources in Europe [34]. Looking in particular at the combined wave-wind resource in Europe, this can be divided into three main sea basins: Mediterranean Sea, North and Baltic Seas and the Atlantic Ocean. 


\subsubsection{The Mediterranean}

This is a closed sea with deep waters, which results in marine energy resource in this sea basin being too weak for viable conversion and consequently, the combined wave and wind energy resource is also weak and is mainly restricted to three possible sites: the French Blue Coast, the Sicily Straight (between Sicily and Tunisia) and the Greek islands

\subsubsection{The North and Baltic}

During recent years, these basins have had special relevance for the development of the offshore wind industry, especially the North Sea. Some of the characteristics that have contributed to this development are: its shallowness (its average depth is $95 \mathrm{~m}$ ), the good wind resources (predominantly from the north), the fact that it is surrounded by some of the most industrialised areas on the world and that there is already an offshore oil and gas industry operating in it [38].

The conditions for the development of the other marine energies, especially wave energy are relatively favourable. Furthermore, the combined wave and wind energy resource is also relevant, and the fact that most of the wind farms are placed in shallow waters, can contribute to the initial development of the hybrid technologies. The combined resource is restricted to three main zones: the North Scottish islands, South West of Norway and the West coast of Denmark.

\subsubsection{The North East Atlantic}

This is an oceanic basin, and its main characteristic is that the water depth at its coasts goes quickly into deep water ranges (reaching more than $100 \mathrm{~m}$ of depth at a few miles from the coast line). Furthermore, this sea basin has the best marine energy resources in Europe, with the strong winds, the fastest tidal stream currents and the highest waves. However, the deep water condition of its coasts it is a strong barrier for the development of those technologies. Therefore, it is expected that this sea basin will be exploited by a future generation of floating wind turbines or floating combined multiplatform systems. The combined wave and wind energy resource is widely distributed, and practically all of the Atlantic Arc is covered with possible combined sites. 


\section{Synergies}

The wave and offshore wind industries share the same hostile marine environment and face many administrative and technological barriers. Moreover, a sustainable exploitation of the marine natural resources, together with the requirement for both industries to reduce costs, provides the incentive for combining the exploitation of waves and offshore winds. This scenario, where wave and offshore wind energy are combined, is advantageous on account of not only the cost reductions that would ensue, but also the synergies between these technologies, which can be divided into two main groups: legislative synergies and project or technology synergies.

\subsection{Legislative synergies}

The following marine uses are susceptible of combinations of one sort or another: offshore wind energy, wave energy, tidal energy, marine biotechnology or deep sea mining. New actors in the maritime sector $[39,40]$, these activities are poised to play a significant role in the maritime economy in the next few decades. They will coexist as parts of a sector where the absence of a common or unified regulation makes it very difficult to develop new initiatives. However, there are some key legislative areas where the combination of some of these actors will lead to strong synergies, such as:

- A common regulatory framework. Like other renewable energies, marine energy projects have long return investment periods, and face relevant energy costs in their early development stage; for this reason their development is based on strategic decisions and political commitments such as: investment priorities, and national or EU energy targets. A clear and stable framework fixing objectives, providing a political support and a stable legislative background would contribute to obtaining a stable environment to develop marine renewables. An example of successful legal regulatory framework is that developed in the UK during the last decade, which has brought the country to lead the ORE industry. 
In this sense it is noteworthy the influence that Energy Act 2004 [41] and the Climate Change Act 2008 [42] had on the sector, acting as a trigger and the key incentive for the UK ORE sector.

- Maritime spatial planning. Traditionally the marine and maritime sectors have been characterised by the absence of a coordinated planning, as opposed to what happens onshore where coordinated regulations and planning have been in place for many years, e.g., land use planning, mining exploitation concessions and natural protected areas. However, in the last years some EU initiatives such as the Maritime Spatial Planning or the Integrated Coastal Protection Management [43] are starting to consider that the coordinated planning over the marine and coastal space, integrating their resources and uses is crucial to ensuring a sustainable development. Notwithstanding, due to the similarities between marine energies, the possibility of their combination would be a strong synergy to advance their development.

- A simplified licensing procedure. As other emerging technologies, marine energy developers face the lack of experience in, and knowledge of, the licensing procedures on the part of public authorities, which results in long consenting periods - in particular regarding the environmental impact assessment, which in some cases could be delayed for years until the final approval for an in-site deployment. Due to the similarities between marine energies, unifying the consenting procedures under the same regime through standard and simplified procedures could signify a combined advantage. In this respect, the recently finished Intelligent Energy for Europe SOWFIA project has produced a set of recommendations and in-depth analysis on wave energy licensing procedures impact assessments and public consultation procedures in Europe [44, 45].

- Infrastructure planning. Electric grid and auxiliary infrastructures are crucial when it comes to offshore developments. Therefore, a proper planning of those infrastructures will 
be fundamental for the development of marine energies such as combined or separate developments.

\subsection{Project or technology synergies}

At a project or technology level the combination of marine energies gains momentum as a real alternative. This is supported by a number of synergies ranging from an increase in the energy yield to a reduction in the operation and maintenance cost. Based on the work by $[23,27,33]$ the project or technology synergies can be defined as follows:

- Enhanced energy yield. The combination of marine energies will increase the global energy yield per unit area of marine space and thereby contribute to a better use of the natural resources.

- Better predictability. The wave resource is more predictable and less variable than the wind resource [19], and the combination of both will reduce the system balancing costs, as seen in $[18,20]$.

- Smoothed power output. For the same weather system the wave climate peaks trail the wind peaks [25]. In consequence, a combined exploitation will result in a reduction of sudden disconnections from the electric grid, an increase in availability (thus reducing the number of hours of non-activity) and a more accurate output forecast.

- Common grid infrastructure. The electric grid infrastructure represents one of the most important costs for an offshore project - up to one third of the entire project [46]. Therefore, the combined production of electricity using a shared grid infrastructure would become an important factor in reducing energy costs.

- Shared logistics. The dimensions and special characteristics of offshore renewable energy projects require the use of expensive specialist marine equipment and facilities, such as port 
space or installation vessels. A combined project where these are shared would also contribute to reducing the costs.

- Common substructure or foundation systems. Where possible, the combination of wave and offshore wind technologies on the same structure, on hybrid platforms or systems, would signify an important reduction in the cost of the substructures compared with separate projects.

- Shared Operation and Maintenance $(O \& M)$. The situation and accessibility conditions of the ORE projects makes it necessary to use dedicated installations by specialised technicians to ensure an effective $\mathrm{O} \& \mathrm{M}$ and to minimise the non-working times of the equipment. The combination of both energies would lead to an important cost reduction as result of the shared use of these installations and technicians.

- Shadow effects. It is clear that the energy extraction of an array of WECs creates a wake that modifies the local wave climate by reducing the mean wave height (shadow effect [27]). Combining WECs and offshore wind parks at the same location, in a way in which this shadow effect can be used to obtain a milder wave climate inside the park (with the proper design, e.g., by locating the WECs along the perimeter of the offshore wind park), may lead to more weather windows for accessing the wind turbines for $\mathrm{O} \& \mathrm{M}$, and to reduced loads on the structures.

- Environmental benefits. The environmental impacts of wave and offshore wind energy are a major consideration in the development of these renewables [47, 48]. The combined option presents an important advantage in environmental terms in that it is likely to have a reduced impact (relative to independent installations), leading to a better utilisation of the natural resources. Moreover, this could result in a transfer of knowledge on the environmental impacts from one sector to another. 


\section{Combined wave-wind systems}

By bringing together two marine renewable technologies with considerable synergies, as discussed above, the combined harnessing of offshore wind and wave energy presents a great potential for development. This is corroborated by some recent EU funded projects: MARINA, ORECCA, TROPOS, MERMAID and H2OCEAN [28-32].

Combined wave-wind systems can be classified according to the technology, water depth (shallow, transition or deep water), or location relative to the shoreline (shoreline, nearshore, offshore). In this work a new classification is proposed based on the degree of connectivity between offshore wind turbines and WECs; it distinguishes: co-located, hybrid, and island systems (Figure 1).

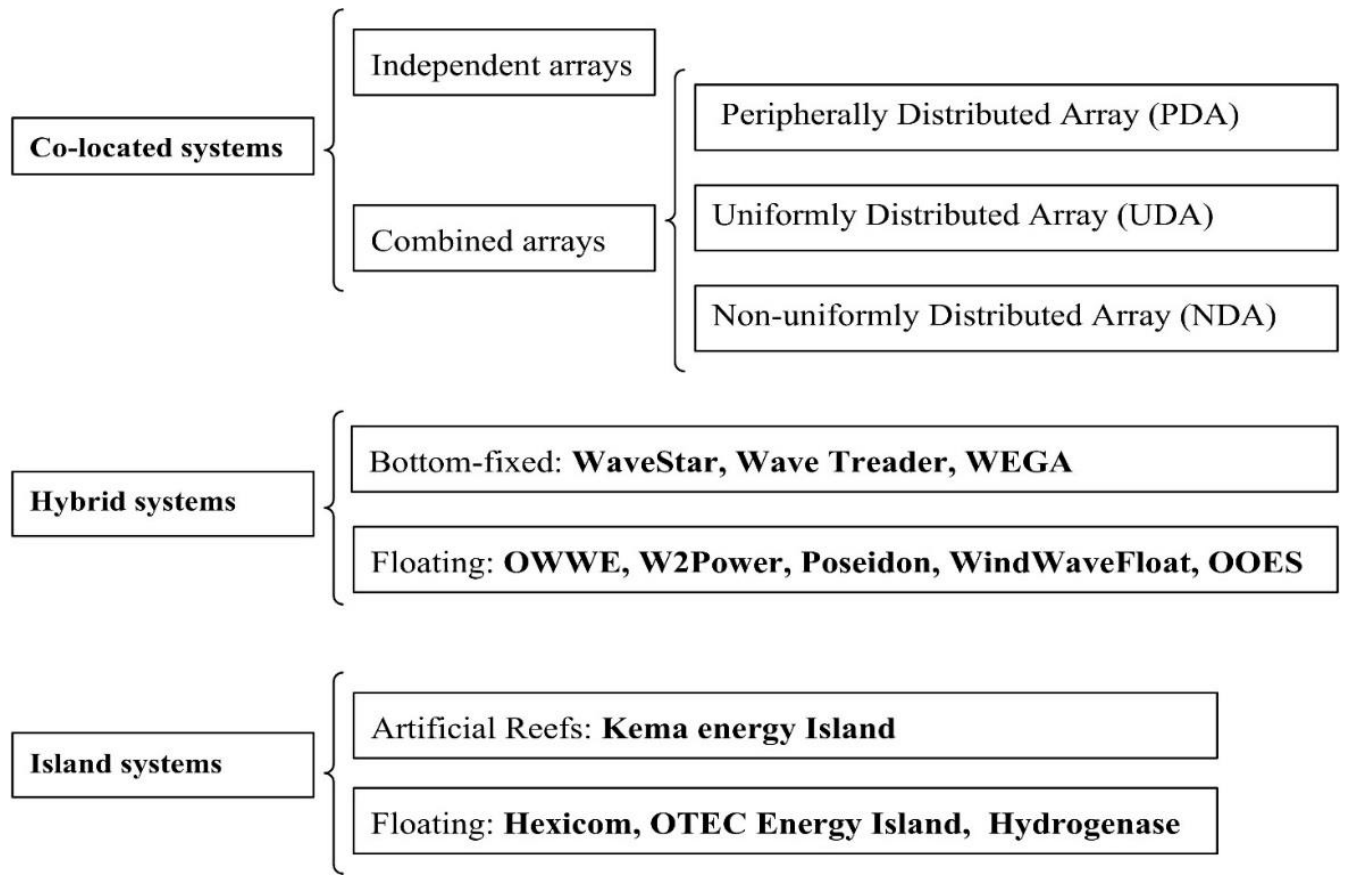

Figure 1: Classification of combined wave-wind technologies

\subsection{Co-located systems}

The simplest option at the current stage of development of wave and offshore wind technologies, co-located systems combine an offshore wind farm with a WEC array with independent foundation 
systems but sharing: the same marine area, grid connection, O\&M equipment and personnel, port structures, etc. In general these co-located systems are based on an offshore wind farm, either bottom-fixed or floating. No major technology developments are required, and the integration consists essentially in appropriate grid planning. The combination of offshore wind and wave energy by means of co-located arrays was investigated from the standpoint of electricity production and grid management by [14]. Co-located systems can be classified into independent arrays and combined arrays.

\subsubsection{Independent arrays}

Co-located independent arrays are those which, while constituting distinct offshore wind and wave farms and occupying different marine areas, are close enough to share the same electric grid connection alongside other services or installations [9]. A schematic representation of a co-located independent system can be seen in Figure 2.

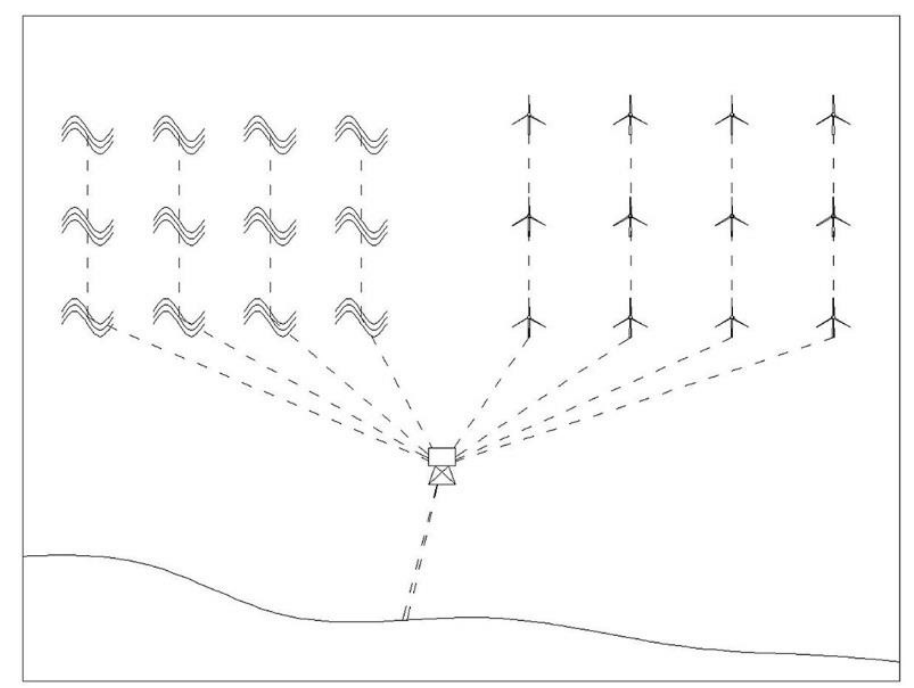

Figure 2: Schematic of a co-located independent array

\subsubsection{Combined arrays}

Unlike co-located independent arrays, in combined arrays the offshore wind and wave devices share the same marine area and relevant infrastructures, so that they constitute a single array. An 
artist's impression of an example of this type of array is presented in Figure 3. (Note: the examples in this section are intended to illustrate the various groups in the classification and do not constitute an exhaustive list).

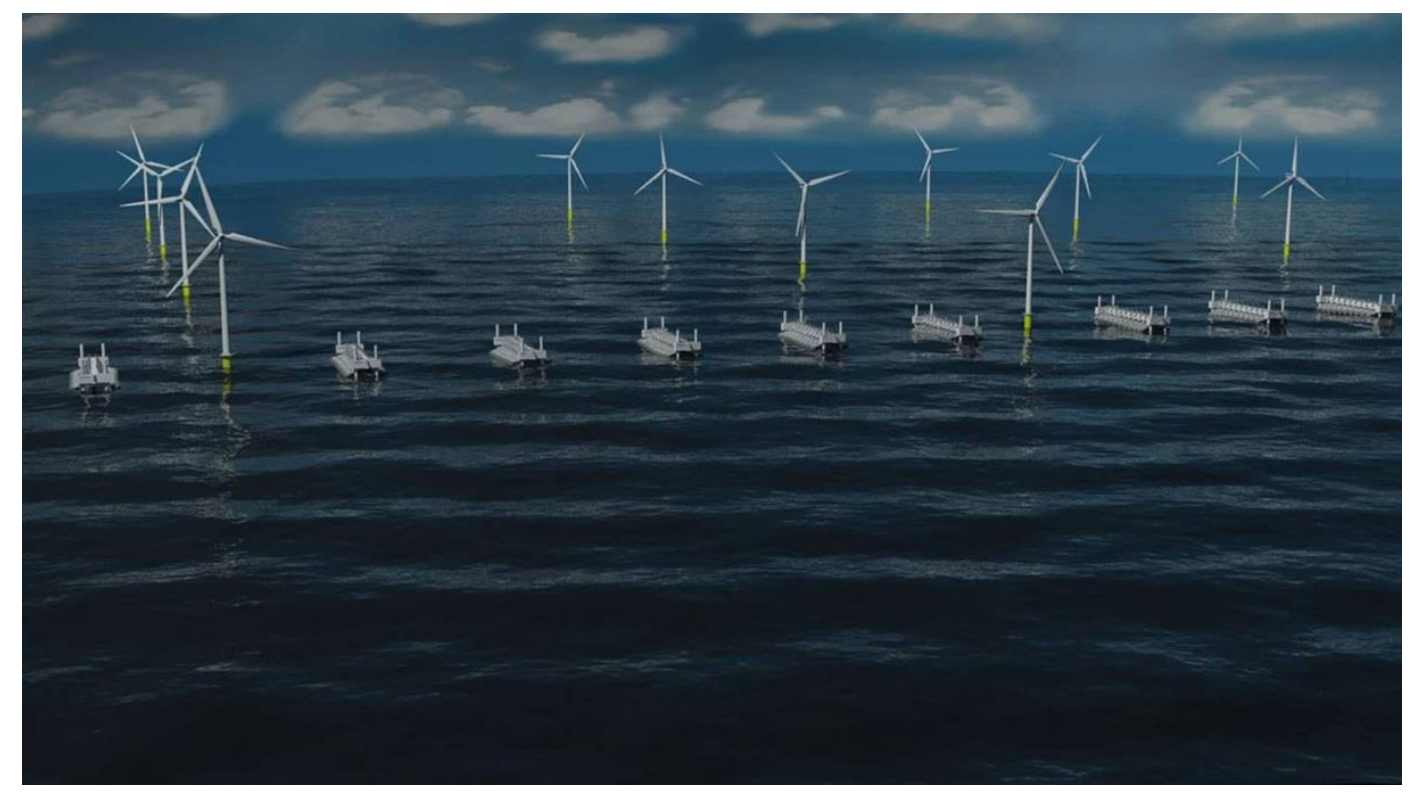

Figure 3: Artist's impression of a combined array (courtesy of Wave Star AS [36] )

Combined arrays can be classified into three categories: Peripherally Distributed Array (PDA), Uniformly Distributed Array (UDA) and Non-uniformly Distributed Array (NDA) (Figure 4). The Peripherally Distributed Array (PDA) deploys the WECs at sections along the perimeter of the array defined according to the prevailing wave direction so that they serve as wave shields. This results in a reduction of wave energy in the inner section of the array. The Uniformly Distributed Array (UDA) is based on a uniform distribution of both offshore wind turbines and WECs throughout the array.

This is the type of combined array that is obtained when WECs are evenly distributed at the gaps between offshore wind turbines in an existing farm. Finally, the Non-uniformly Distributed Array (NDA) consists in a non-uniform distribution of the WECs throughout the offshore wind farm. An example of this type is an array where, on the basis of a standard offshore wind farm layout, the 
WECs are positioned so as to maximise their performance considering the interaction with the other WECs and the wind turbines.
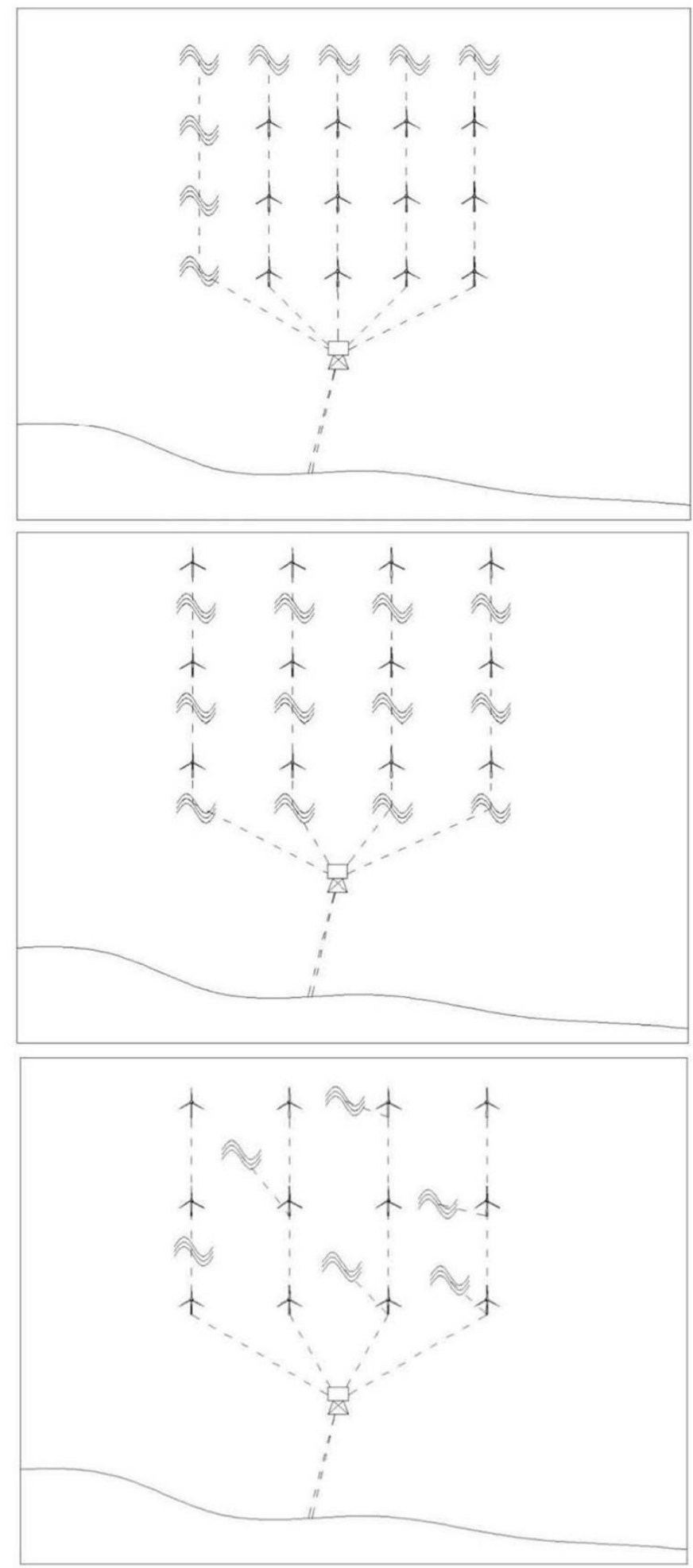

Figure 4: Schematic of co-located combined systems: from top to bottom, Peripherally Distributed Array (PDA), Uniformly Distributed Array (UDA) and Non-uniformly Distributed Array (NDA). 


\subsection{Hybrid systems}

Hybrid systems are part of the wider family of multipurpose platforms, i.e., offshore structures on which different marine uses are combined, such as: ocean energies, offshore wind, aquaculture, transport and marine leisure $[25,26]$. For the purposes of this work, a hybrid system combines an offshore wind turbine and a WEC on the same structure. Over the last years, two EU funded projects, MARINA and TROPOS, dealt with wave and offshore wind hybrid systems. On the one hand, MARINA [28] focused on the establishment of a set of criteria for the evaluation of multi-purpose platforms for Marine Renewable Energy (MRE). On the other, TROPOS [30] is aimed at developing a floating multi-purpose platform system for deep water.

According to their substructure, hybrid systems can be classified (Figure 1) into bottom-fixed and floating, appropriate for shallow or transitional and deep water, respectively.

\subsubsection{Bottom-fixed hybrids}

Bottom-fixed wave and offshore wind hybrids are ground-breaking systems based on an evolution of the current substructures used by the offshore wind industry to accommodate a WEC [23]. Alternatively, a bottom-fixed hybrid could be conceived by integrating a WEC into an existing offshore wind turbine, strengthening the substructure as required. Notwithstanding; none of both alternatives are not without difficulty, and further research should be conducted to understand the interaction between the WEC and the offshore wind substructure.

Recently a number of bottom-fixed wave and offshore wind hybrid device concepts were put forward, among which: (i) Wave Star, proposed by the eponymous Danish wave energy developer [36], with a WEC mounted on a monopile offshore wind substructure (Figure 5); (ii) Wave Treader, by Scotland's Green Ocean Energy [37]; and (iii) WEGA, a gravitational wave energy absorber developed by Portugal's Sea For Life [49]. 


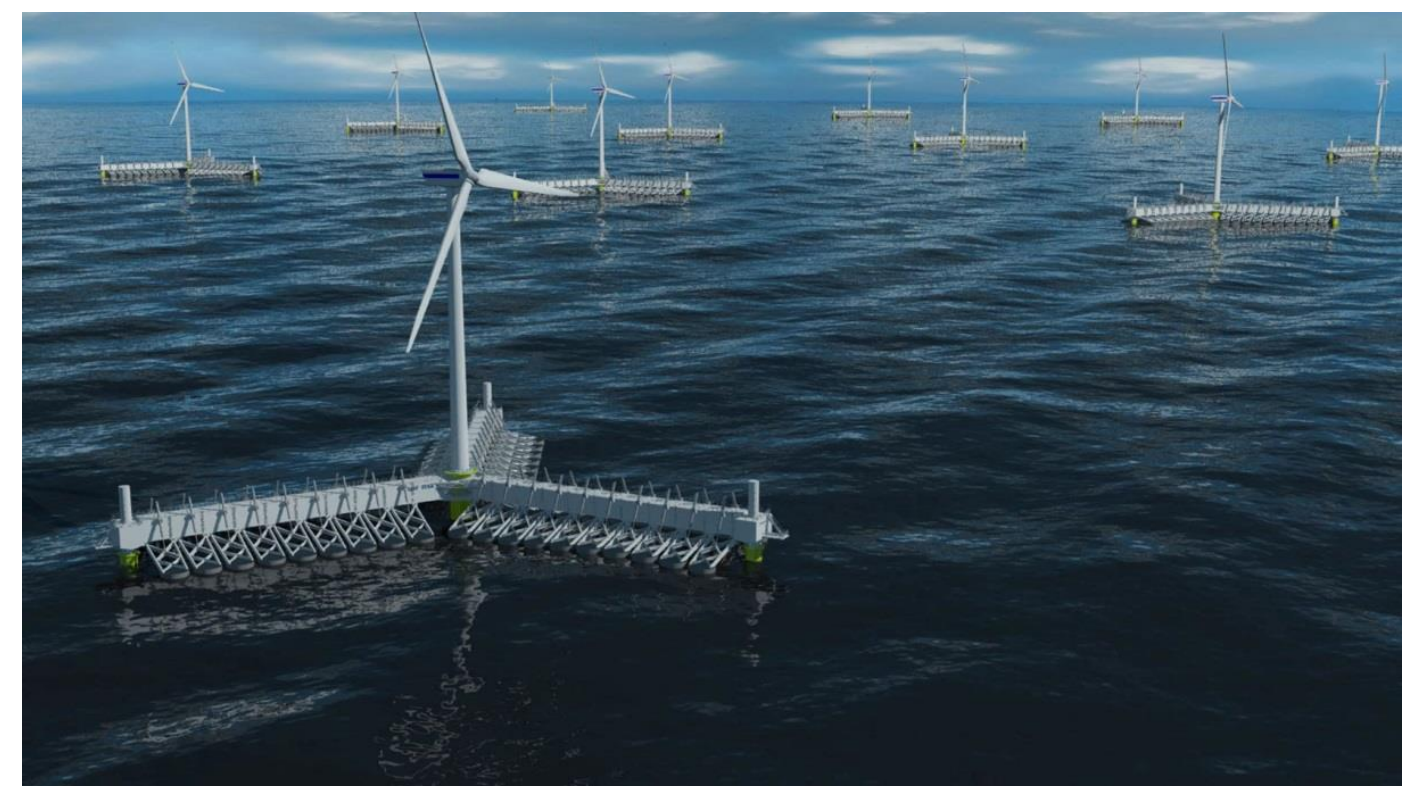

Figure 5: Artist's impression of a hybrid system (courtesy of Wave Star AS [36])

\subsubsection{Floating hybrids}

Floating wave and offshore wind hybrids are a new concept that has begun to be considered with the advent of floating offshore wind prototypes in recent times, with a number of developers developing floating substructures that combine offshore wind turbines with WECs. The interest in floating hybrids stems in part from the larger wave resource that exists in deep water, in part from the lack of continental shelf, and hence of water depths suitable for bottom-fixed concepts, in a number of countries with a relevant wave resource, such as Spain or Portugal.

An artist's impression of the floating hybrid W2 Power, proposed by Pelagic Power AS [50], is shown in Figure 6. Other examples of hybrids include: OWWE, by Norway's Ocean Wave and Wind Energy Ltd. [51]; Poseidon Floating Power, by the Netherlands' Floating Power Plant AS [52]; WindWaveFloat, by the US Principle Power [53]; and the Offshore Ocean Energy System, by the US Float Inc. [54]. 


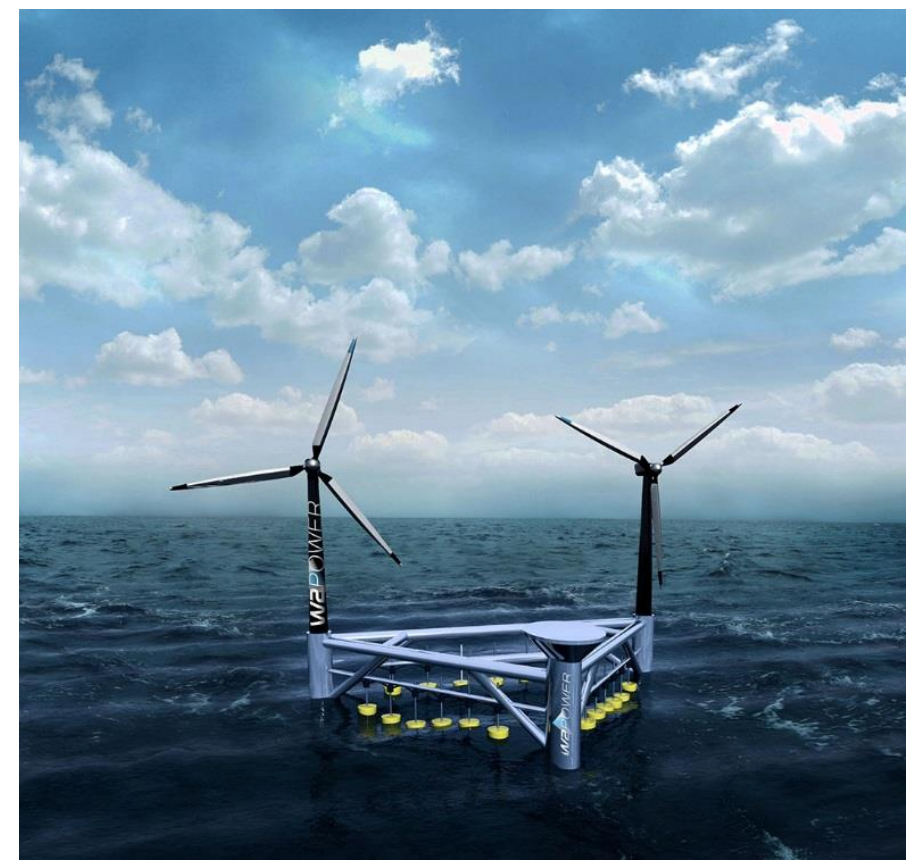

Figure 6: Artist's impression of a floating hybrid system W2Power (courtesy of Pelagic Power AS [50])

\subsection{Island systems}

The third and last family of combined wave and wind energy technologies is island systems. As with hybrid systems, island systems are offshore multipurpose platforms. The differences with hybrid systems lie in that islands tend to be much larger and, perhaps more importantly, unify the combined exploitation of more than two marine resources on the same platform. Island systems can be divided into artificial or floating islands.

\subsubsection{Artificial islands}

Artificial energy islands are typically based on a large reef or dyke, and can serve as platforms for large-scale electricity storage, MRE converters, and other marine activities. The most relevant concept of this type is the Kema Energy Island or Large-scale electricity storage from the Dutch DNV KEMA Consulting [22]. 


\subsubsection{Floating islands}

Floating energy islands are large floating multipurpose platforms, typically of smaller dimensions than artificial islands but larger than most vessels, where a combined harnessing of marine resources can be carried out. The proposed $50 \mathrm{MW}$ platform project by the UK's Energy Island Ltd. [55] is an example of this type of island system.

\section{Substructures for combined systems}

To develop the combined wave-wind systems defined in the previous section it is necessary to advance a step forward in the technology development. Substructures play a key role in this development, for they are the natural link between both technologies and the environment. Therefore, a good understanding of the current substructure technologies and their limitations is crucial to understanding the possibilities of the combined harnessing of winds and waves.

Offshore wind turbines were developed during the last two decades basically by applying the existing and well-known onshore wind technology to offshore sites. However, during the last decade, the industry has developed some specific offshore technologies and nowadays the main differences with onshore wind turbines lie in the substructure. A detailed description of offshore wind technology can be found in, e.g., [46, 56, 57]. 


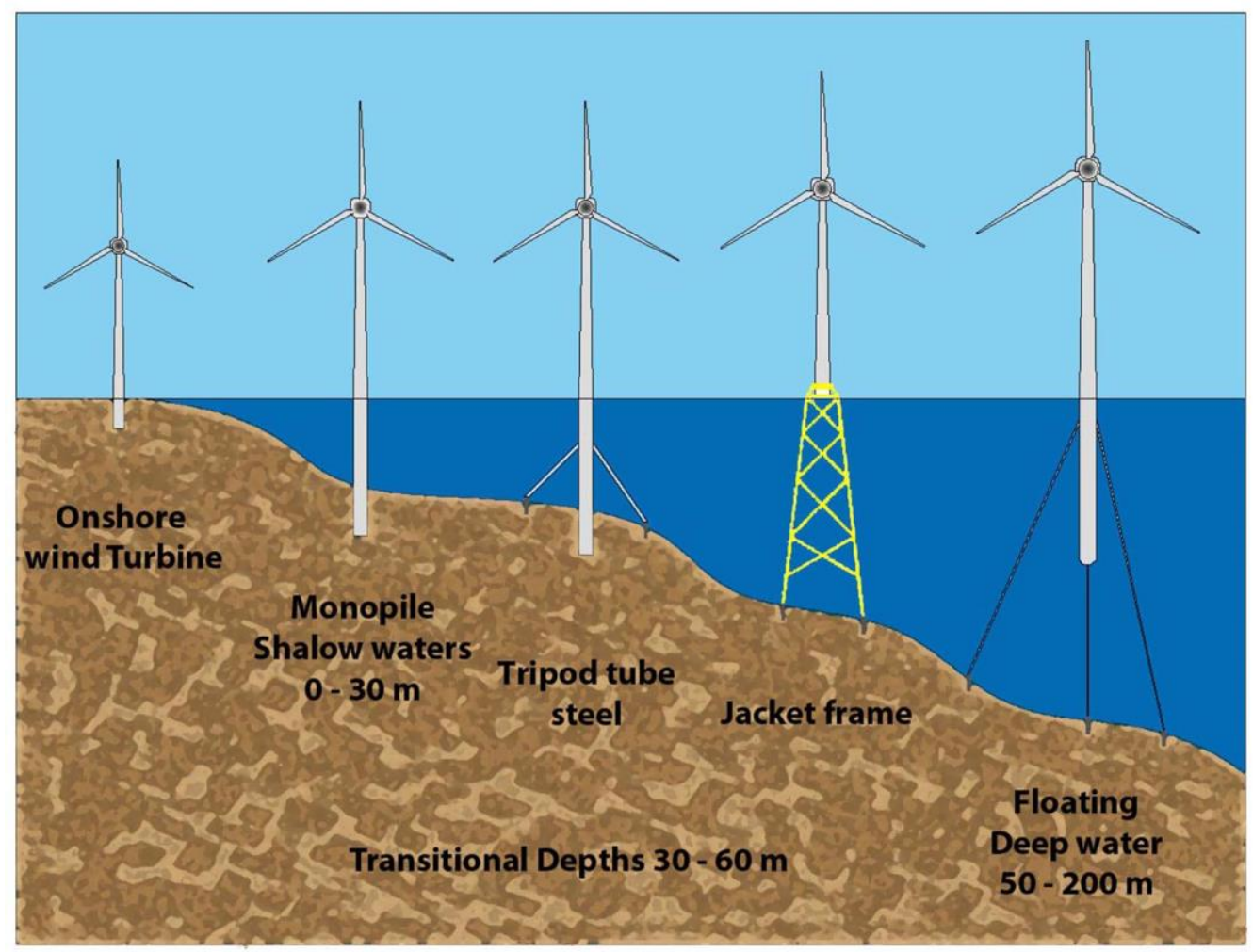

Figure 7: Schematic of current substructure technologies

In this work offshore wind turbines, and their substructure systems, can be classified according to water depth as follows: (i) shallow water, (ii) transitional water, and (iii) deep water or floating. Within each group, subgroups are defined based on substructure type. A schematic is presented in Figure 7, and the classification in Figure 8. The rationale for this classification is that substructure systems are essential in integrating offshore wind and wave energy; indeed, the substructure is the part of the offshore technology that interacts directly with the WEC. Furthermore, the technical characteristics of the different substructure systems will result in different ways of combining both energies, and at the same time will constrain the possibilities. Detailed information on the different categories can be found in [46, 58-63]. 


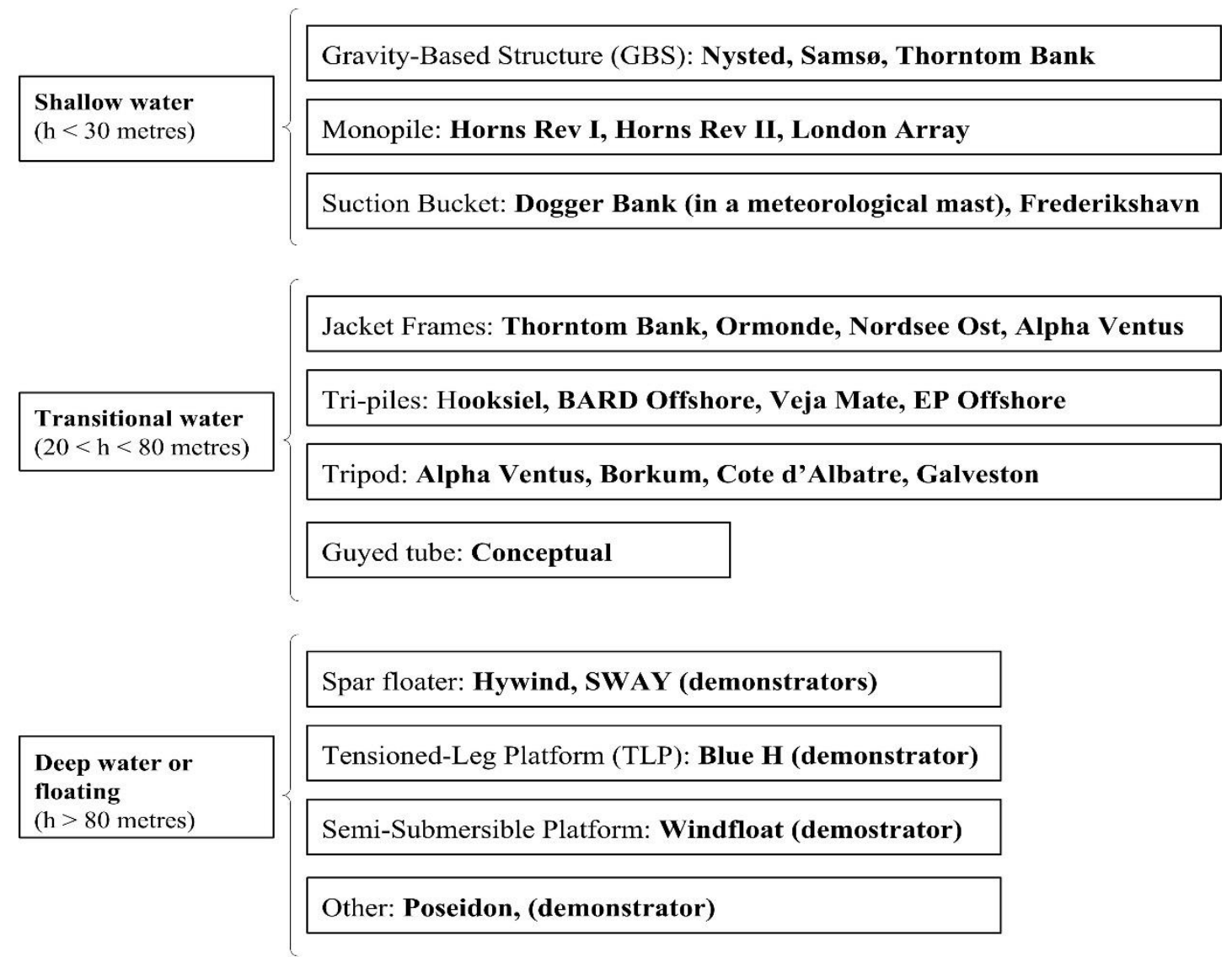

Figure 8: Substructure types according to water depth

\subsection{Shallow water substructures}

Shallow water substructures for offshore renewables developed over the last two decades in parallel with the offshore wind industry in the shallow waters of the North Sea. Monopiles and Gravity Based Structures (GBSs) are the most representative types of substructures, with a total cumulative share until 2012 of $74 \%$ and $16 \%$, respectively [64].

\subsubsection{Gravity-base structure}

GBSs were developed on the early nineties with the first offshore wind parks for very shallow waters. These are heavy concrete structures (Figure 9) which are built onshore, at specialist construction sites like shipyards, then lifted and deployed at their final location offshore, and loaded with ballast (e.g., sand, rocks, iron or concrete). While GBSs constitute a suitable solution for shallow water sites, with average depths between $5 \mathrm{~m}$ and $20 \mathrm{~m}[63,65]$, their main limitation is that 
their cost increases quickly with water depth. This solution was adopted in numerous offshore wind farms during the last two decades, among which Nysted (Denmark) or Thorntom Bank I (Belgium).

\subsubsection{Monopile}

Monopiles (Figure 9) are the simplest technical solution for shallow water and, owing to their relatively low cost, have been selected by most offshore wind developers in the last decade. The monopile consists in a pipe that is driven into the seabed and connected with the wind turbine mast through a transition piece. The main limitations of monopoles are: the increase of the steel cost in water depths greater than $30 \mathrm{~m}$, and the uncertainty associated with scouring on the seabed. Nowadays, monopiles are the most popular substructure alternative for shallow water locations, i.e., with average water depths between $10 \mathrm{~m}$ and $30 \mathrm{~m}[63,66,67]$. Representative examples are: Horns Rev I (Denmark), Horns Rev II (Denmark) and London Array (UK).

\subsubsection{Suction bucket}

Suction bucket substructures (Figure 9) are an innovative concept designed to cover a larger range of water depths at a low cost. These substructures are designed to cover the range from $5 \mathrm{~m}$ to $60 \mathrm{~m}$ of water depth with a lower cost in comparison with the other alternatives. A prototype of this substructure technology was commissioned for the Danish offshore wind farm of Frederikshavn in 2009, and two met-mast towers using this type of substructure can be found at Dogger Bank (UK) and Horns Rev II (Denmark) [68]. 

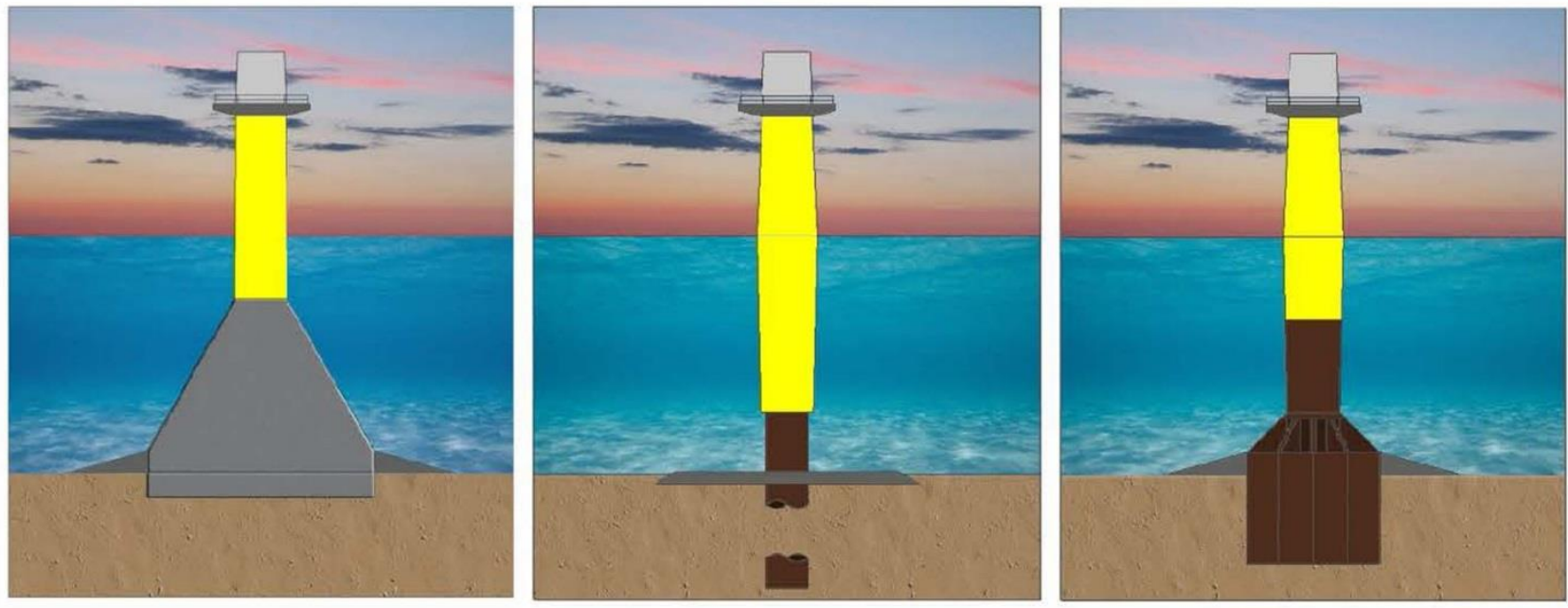

Figure 9: Shallow water substructures: from left to right, GBS, monopile and suction bucket

\subsection{Transition water substructures}

Transitional waters substructures are those designed to reach water depths between 30 and $80 \mathrm{~m}$. These systems are starting to be considered by the industry, in order to reach deeper waters. They include some more complex technologies, such as: jacket frames, tri-piles and tripods $[46,69,70]$.

\subsubsection{Jacket frame}

Jacket frame (Figure 10) substructures have been consolidated during the last couple of years as the most extended offshore renewables substructure for transitional waters $[64,71]$. This system comes from an adaptation to the offshore wind industry of concepts that have been in use in the oil and gas industry for decades. Their main advantage lies in the possibility of reaching higher depths (up to $80 \mathrm{~m}$ ). Their main limitations are due to the high construction and installation costs [72-74]. Several offshore wind parks have adopted this substructure system during recent years; some examples are: Thorntom Bank (Belgium), Ormonde (UK) and Alpha Ventus (Germany).

\subsubsection{Tri-pile}

The tri-pile (Figure 10) substructure system is a new concept developed to reach deeper waters than with the shallow water systems, up to $60 \mathrm{~m}$. This technology consists of three monopiles linked together through a joint piece at the top. The main advantage of this solution is the simplicity of the 
installation, which is done by installing three monopiles and then adding the upper joint [75]. Some examples of this substructure can be found at: BARD Offshore (Germany), Veja Mate (Germany) and the demonstrator prototype at Hooksiel (Germany).

\subsubsection{Tripod}

Tripods (Figure 10) are the last kind of transitional waters substructures for offshore renewables. This system is an innovative concept that consists on a central pipe that lies on a tripod tubular frame configuration at its bottom part. This uses three small seabed driven piles at each leg of the tripod to link it to the seabed. The main advantage of the tripod system is its larger base, which gives it an increased resistance against overturning. However, its large dimensions make its installation difficult and increases consequently its cost $[67,69,76]$. Some examples of offshore wind farms that employ this substructure are: Alpha Ventus (Germany) and Cote d'Albatre (France).
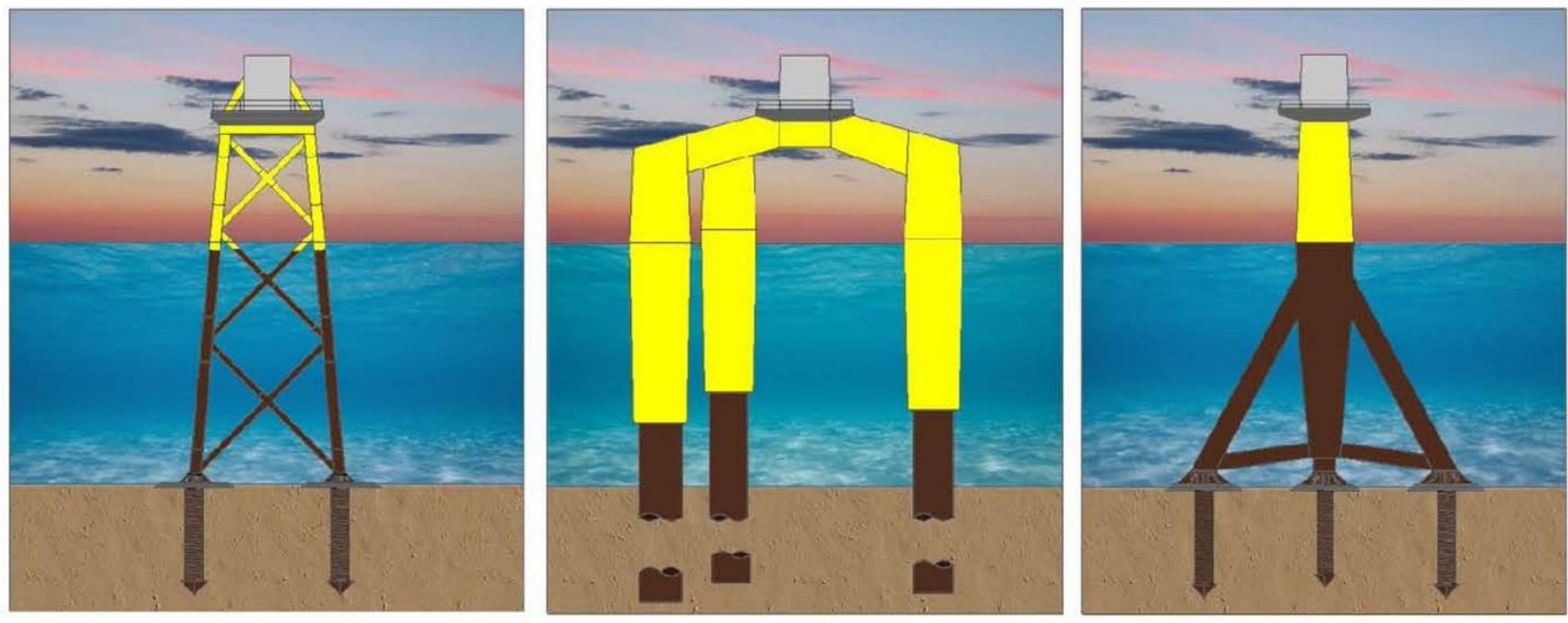

Figure 10: Transition water substructures: from left to right, jacket frame, tri-pile and tripod

\subsection{Deep water or floating substructures}

Finally, deep water or floating substructures are the industry approach to harness the huge resource that exists at deep water sites, such as at the European Atlantic coast. The offshore wind industry has been competing during the last few years to go deeper offshore and therefore develop an 
appropriate device for such emplacements. Nonetheless, floating foundations are still at an early stage of development, and many different prototype concepts are being tested at scale level in real or laboratory conditions. These different concepts can be classified into three main groups: spar floaters, Tensioned-Leg Platforms (TLP) and Semi-Submersible Platforms (SSP).

\subsubsection{Spar floater}

A spar floater substructure (Figure 11) is based on a spar buoy configuration used in offshore oil and gas. This bases its buoyancy and stability on a long and slender cylinder that goes deep below the water surface. The large mass of this cylinder contributes to reduce the wave induced motions. The main advantage of this system is on its good dynamic response and stability. A spar floater was selected for the Hywind and SWAY floating offshore wind prototypes (Norway) [77, 78].

\subsubsection{Tensioned-Leg Platform}

TLPs (Figure 11) are submerged platforms tethered to the seabed by means of pre-tensioned mooring cables. These pre-tensioned mooring lines contribute to a drastic reduction on the heave movement, increasing the system's horizontal stability. The main advantage of this system lies on its low cost, however; the dynamic efforts on the mooring lines are its main weak point $[69,79,80]$. An example of using this system for offshore renewable energy is the Blue H prototype (The Netherlands)
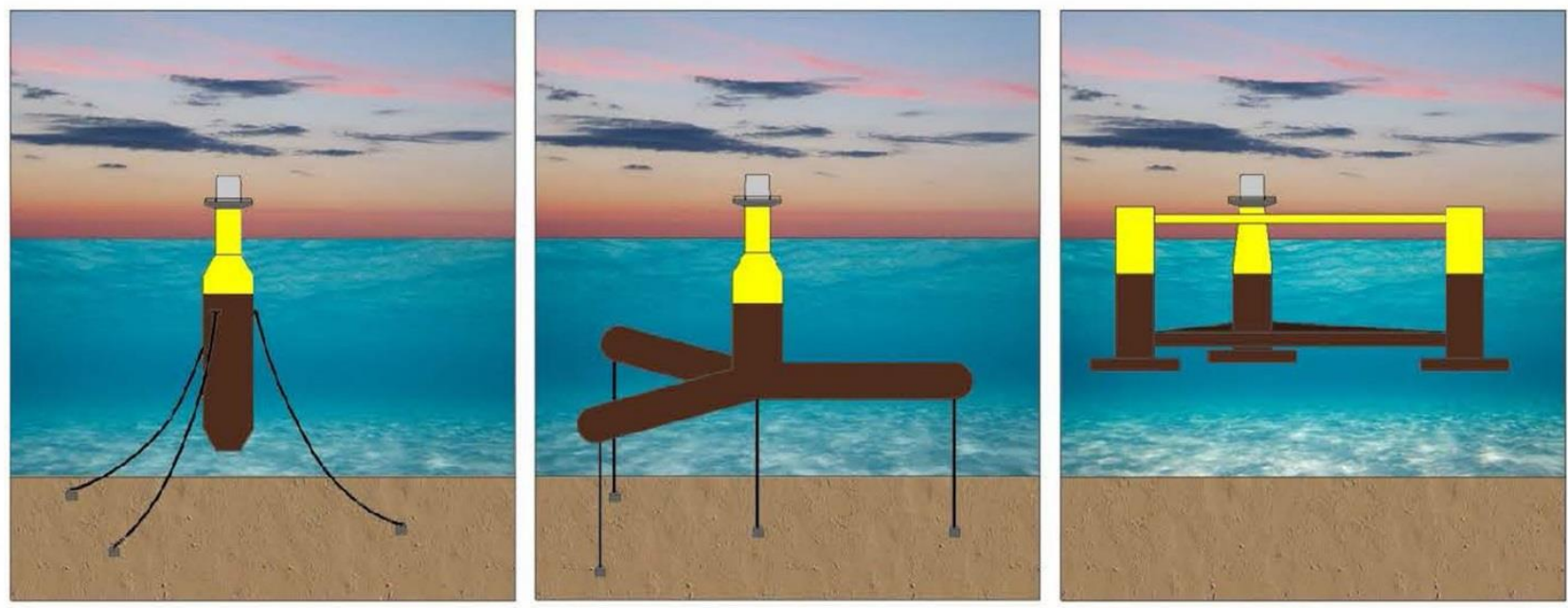
Figure 11: Deep water or floating substructures: from left to right, spar floater, TLP and SSP

\subsubsection{Semi-Submersible Platform}

SSPs systems (Figure 11) also come from concepts already existing in the oil and gas industry. These are based on a barge or semi-submersible structure that relies on its buoyancy to support the upper structure above the water. On one hand, its main advantage is on its flexibility, as it can be easily moved from one emplacement to another one or adaptable for different water depth emplacements. On the other hand, its major problem comes from the non-easily avoidable movements of the system $[50,52,53,81]$. Furthermore, this type of substructure has been in some concepts, such as: WindFloat (USA), W2Power (Norway) and Poseidon (The Netherlands).

\section{WEC technology for combined systems}

As well as with substructures, a good understanding of WEC technologies is crucial for a proper understanding and development of combined wave and wind systems. Wave energy conversion is still a relatively young technology, and intensive research efforts have been devoted over the last years to the development of WECs [82]. These technologies were reviewed by a number of authors [83-89]. Based on the principle of energy capture, they can be classified into: OWC, oscillating bodies and overtopping devices. A short description of the three types is provided below.

\subsection{Oscillating Water Columns}

OWCs are conversion devices with a semi-submerged chamber, keeping a trapped air pocket above a column of water. Waves cause the column to act like a piston, moving up and down and thereby forcing the air out of the chamber and back into it. This continuous movement generates a reversing stream of high-velocity air, which is channelled through a turbine-generator group to produce electricity $[90,91]$.

The main advantage of these systems lies in their reliability. OWCs are simple and well-proven devices, with usually no moving parts other than the air turbine. Moreover, this technology is well 
suited to all the possible environments for wave energy extraction, and prototypes have been developed for shoreline, nearshore and offshore emplacements. Some representative examples of OWC devices are: GreenWave (UK), Wavegebs Limpet (UK), Pico Plant (Azores, Portugal), Mutriku (Spain), OE Buoy and Oceanix (Australia). A schematic representation of a breakwatermounted OWC and a picture of the Mutriku plant can be seen in Figure 12.

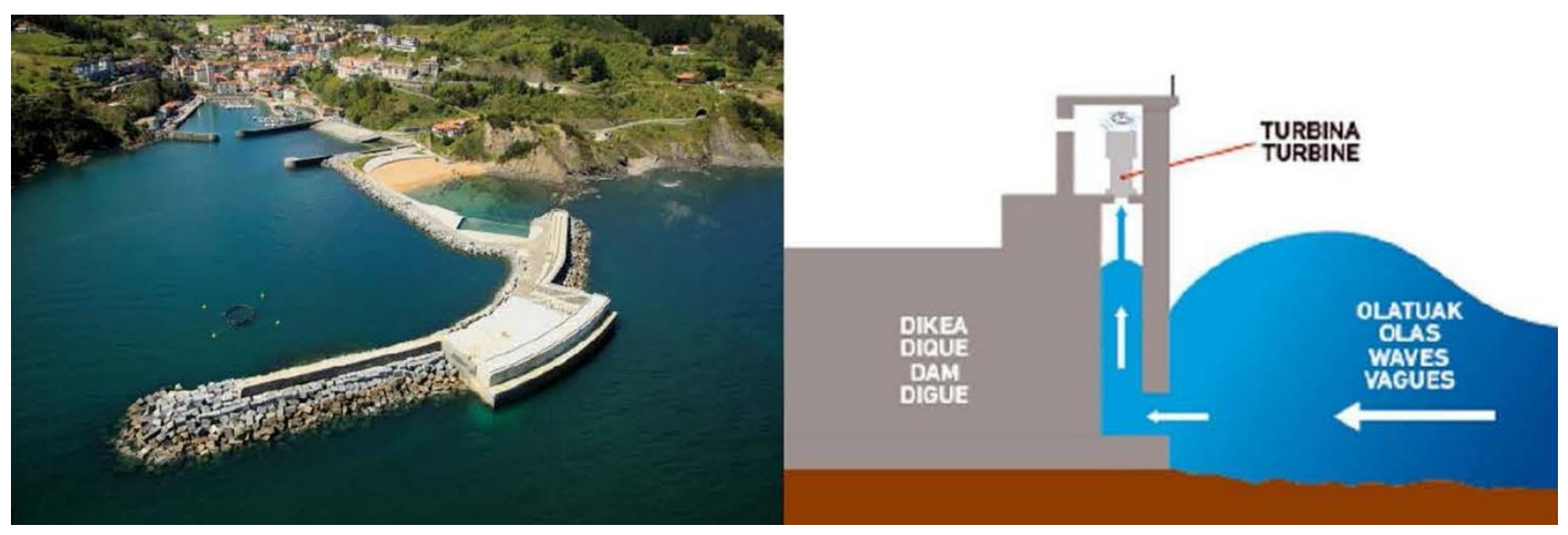

Figure 12: Mutriku's breakwater-mounted OWC (left) and schematic of the system (courtesy of EVE [92])

\subsection{Oscillating Bodies}

Oscillating bodies are the more diverse group of WECs. This group brings together all of those conversion devices that harness the wave energy through a body, usually a floater or a buoy, which is forced to maintain an oscillatory movement i.e. a heave, roll or pitch motion. Oscillating bodies are either floating or bottom fixed devices, designed to exploit the more powerful deep water wave regimes. In general, they are more complex than OWCs, in particular as regards the Power Take Off (PTO) systems. In fact, the many different concepts and methods to transform the oscillating movement into electricity have given rise to many different PTO systems, e.g. hydraulic generators with linear hydraulic actuators, linear electric generators, piston pumps, etc.

The main advantage of these systems lies on their small size and the fact that most of them are floating devices, which makes them very versatile. However, on the minus side, a clear technology 
has not emerged yet, and more research should be carried out to increase the PTO performance and avoid certain issues with the mooring systems. Some representative devices of oscillating bodies are: Pelamis (UK), PowerBuoy (US), AWS (US), Oyster (UK) and WaveStar (Denmark). A representation of some oscillating bodies can be seen in Figure 13.

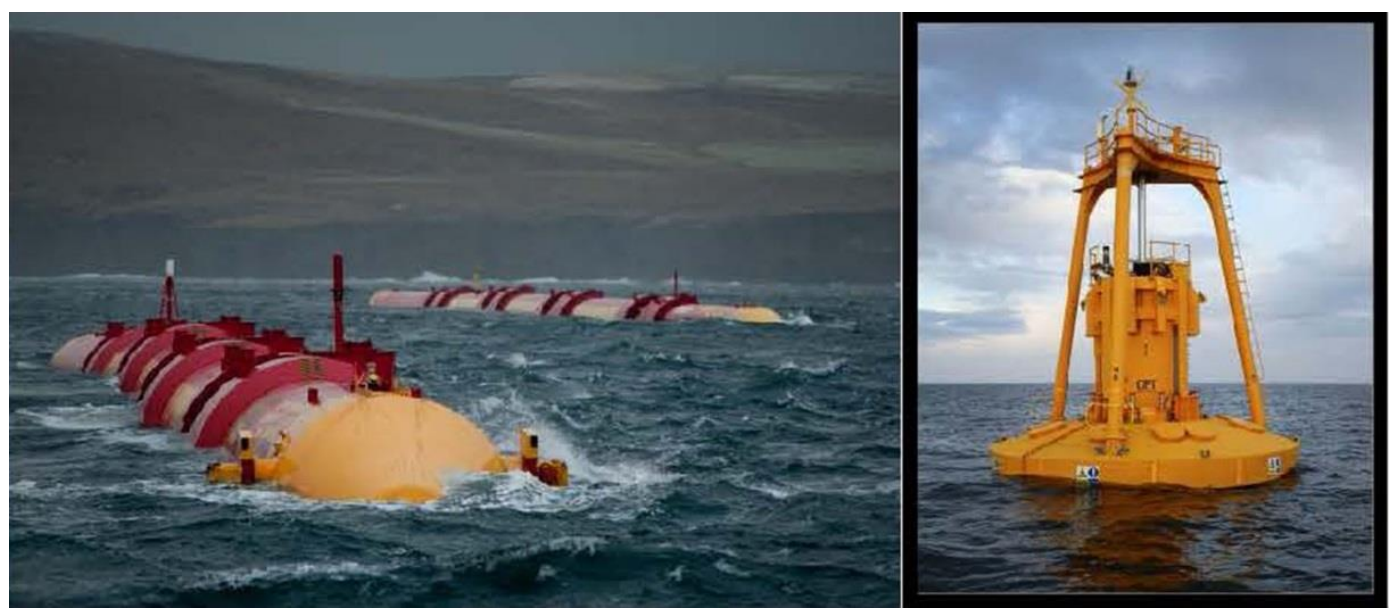

Figure 13: Examples of oscillating body converters: Pelamis II, left (courtesy of Pelamis Power, left [93]) and PowerBuoy, right (courtesy of the Ocean Power Technologies Inc, right [94])

\subsection{Overtopping}

Finally, overtopping conversion devices are usually either offshore floating or shoreline fixed water reservoir structures, normally with reflecting arms to focus the wave energy. As waves arrive, they overtop a ramp structure and are restrained in the reservoir. The potential energy due to the height of collected water above the sea surface is transformed into electricity using conventional low head hydro turbines [95-97].

The main advantage of these systems lies in their simplicity, i.e. they stores water and, when there is enough, let it pass through a turbine. Notwithstanding, its main downsides are the low head (in the order of 1-2 m), or their large dimensions that a full scale overtopping device would have. Some representative overtopping devices are: WaveDragon (Denmark), Seawave Slot-Cone Generator (Norway), or WaveCat (Spain). Some examples of overtopping converters can be seen in Figure 14. 


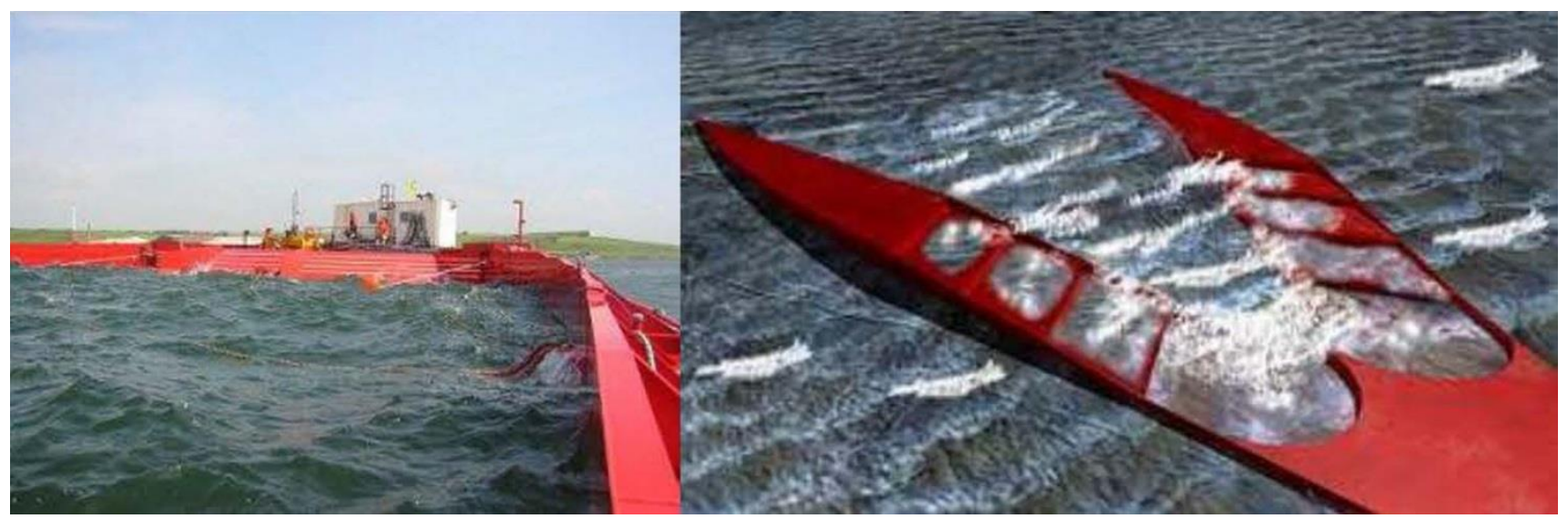

Figure 14: Examples of overtopping converters: WaveDragon, left (courtesy of Wave Dragon AS, left[98]) and WaveCat, right (courtesy of the COAST Research Group at Plymouth University [99], [100])

\section{Technology development issues}

Currently there are no combined wave-wind devices operating in the sea, and only a few prototypes have been proposed so far. Furthermore, there are no WEC farms or arrays of multiple devices operating in the sea. From this technological gap in comparison with the offshore wind sector raises a number of challenges which need to be faced to make combined wave-wind energy becoming a reality. The most relevant of these challenges can be defined as follows:

- Longer development times; the early stage of development of WEC technologies could entail longer development times, which would increase project costs.

- Insurance; the lack of experience in co-located projects could mean higher insurance costs.

- Accident or damage risk; co-locating floating WECs near OWTs could increase the risk of accident or damage in case of a mooring failure on the WEC.

- Site-selection compromise; optimising the site selection for a combined concept could be not ideal for wave and wind compared with the stand-alone option. 
Nevertheless, these challenges represent an opportunity to develop new research and technological knowledge which with further development and innovation could generate technological improvement. In addition, the influence of these challenges varies depending on the type of combined wave-wind system, e.g. for a co-located system where both technologies are well developed, a further device development would not been required, as the current technology is mature enough, however, for a hybrid system further in-deep WEC substructure interaction should be considered.

In order to understand the implications of combining wave and offshore wind energy technologies and its development requirements, these can be considered for each type of combined system. For co-located systems to be commercially viable, the interaction between the WECs and offshore wind farms will need to be studied in order to and minimise the possible risk of accident or damage (e.g. in case of a mooring failure on the WECs). For hybrid systems, an iterative conventional development procedure will need be done by combining techniques used in wave and offshore wind energy development. Finally, for energy island system, a longer research and development is required as the technology gap is greater here.

For these systems to be thoroughly developed, they will need to go through various steps of numerical and scaled testing in laboratories to understand the WEC interaction within the offshore wind substructures and with the local environment (wave field and coast line). These tests should be performed subject to Technology Readiness Level (TRL), to assessment protocols or recognised scientific procedures [82, 101-104].

\section{Economic aspects}

In the current position, the wave energy industry is passing the so-called valley of death in technology development and beginning to acquire the necessary experience to reduce its energy costs; and the offshore wind industry is reducing operational costs and scaling up turbines to achieve 
more competitive energy prices. Combined wave-wind systems could represent the right approach to solve both requirements in a symbiotic union and the synergies presented in Section 2 of this paper shall be considered as strong links between technologies. Thereby on the one hand, WECs could provide an important operational cost reduction to offshore wind farms by sharing O\&M costs or by being used as shields to increase weather windows for access to the wind turbines. On the other hand, offshore wind farms could reduce the energy cost of wave energy by sharing the grid connection, the logistics and common infrastructures [27].

\section{Conclusions}

This paper has presented an overarching analysis of the most relevant aspects related to combined wave and offshore wind energy systems. It has stablished the different areas related to these systems aiming to establish a reference frame to be used in future research and developments. The different combined wave and offshore wind systems studied so far have been reviewed presenting a novel classification based on the extent to which the wave and offshore wind technologies are linked. It distinguishes co-located, hybrid, and island systems. Based on this classification, an extensive review of the different concepts is presented.

The existence of an abundant combined resource together with the strong synergies existing between both technologies makes a compelling argument for combining wave and offshore wind energy to achieve a sustainable and rational exploitation of the offshore energy resources. However, fundamental research is highlighted as crucial to test the validly, sustainability and integration of these combined systems; and to determining to what extent these new or adapted WECs are suitable to be combined with current offshore wind farms.

In addition to those mentioned above, there are also other important issues to be considered:

- Abundance of combined wave-wind resource, particularly in Europe and specially in Europe's North Atlantic sea basin. 
- Wave and offshore wind technologies share many objectives, ranging from the legislative level, at which a clearer, simplified framework will facilitate to attract investments, to that of the project or technology objectives, at which their combination will contribute to the development of both technologies.

- Among all the strong points in common between wave and offshore wind energies there are three that stand out over the others: the possibility to share common and costly infrastructures (e.g. the grid connection or foundations); the possibility to share operational cost by sharing common O\&M teams of facilities; and the possible shadow effect (i.e. to use WECs as to shield the offshore wind park and reduce the wave height at the inner part, increasing in this way the weather windows to access the wind turbines).

- For combined wave-wind energy to become commercially viable, the main technological aspects to be resolved are the substructure and the wave energy conversion technology. The different solutions were classified and briefly presented, and their degree of development and prospects discussed.

- The major technological and economic challenges that combined wave and offshore wind systems face were identified and discussed. Analysing their implication for each of the systems considered and giving a brief glimpse of the major economic pros and cons of these systems.

Although, most of the Research and Development carried out so far has been focused on hybrid systems, nonetheless, co-located systems, due to their lower risk and development costs, are likely to be the first approach for a combined harnessing of both energies. Within the hybrid systems special attention should be paid to floating devices. Their development is being carried out in conjunction with floating wind substructures, with the WECs contributing to attenuating movements and improving stability - in addition to their primary purpose of generating additional energy. Finally, island systems are a relatively new concept, at an early stage of development. 
In sum, this article integrates previous works from around the world to produce a complete review of combined wave and offshore wind energies, by reviewing the resource, their common synergies, presenting a comprehensive classification of the solutions, and discussing the stage of development, challenges and prospects of the different technologies involved in this nascent, and promising sector.

\section{Acknowledgements}

This work was carried out in the framework of the Atlantic Power Cluster project (Atlantic Area Project nr. 2011-1/151, ATLANTICPOWER), funded by the Atlantic Area Operational Transnational Programme as part of the European Regional and Development Fund (ERDF) of the European Commission, and as part of a $\mathrm{PhD}$ project supported in part by the School of Marine Sciences and Engineering of Plymouth University. The authors are grateful to Mr Matthew King and Mr Iain Shepard, of unit C1 at DG MARE (European Commission), and Ms Anne Benedict of EWEA, for helpful discussions on offshore renewables and their synergies, and to the COAST Research Group of Plymouth University, EVE, Pelagic Power AS, Pelamis Wave Power, Wave Dragon AS and Wave Star AS.

\section{References}

[1] Bahaj AS. Generating electricity from the oceans. Renewable and Sustainable Energy Reviews. 2011;15:3399-416.

[2] Iglesias G, Carballo R. Wave energy potential along the Death Coast (Spain). Energy. 2009;34:1963-75.

[3] EU-OEA. Oceans of Energy. European Ocean Energy Roadmap 2010-2050. Bietlot, Belgium: European Ocean Energy Association,; 2010. p. 1-36.

[4] Jeffrey H, Sedgwick J. ORECCA. European Offshore Renewable Energy roadmap. September 2011 ed2011. p. 1-201. 
[5] Moccia J, Arapogianni A, Wilkes J, Kjaer C, Gruet R. Pure Power. Wind energy targets for 2020 and 2030. Brussels, belgium: European Wind Energy Association; 2011. p. 1-97.

[6] EWEA, ECN, 3E, SOW. Delivering offshore electricty to the EU. Spatial planning of offshore renewable energies and electricity grid infrastrutures in an integrated EU maritime policy. 2012. p. 80.

[7] EWEA. Wind in power: 2011 European statistics. Brussels, belgium: European Wind Energy Association; 2012. p. 1-11.

[8] Veigas M, Iglesias G. Wave and offshore wind potential for the island of Tenerife. Energy Conversion and Management. 2013;76:738-45.

[9] Veigas M, Iglesias G. A Hybrid Wave-Wind Offshore Farm for an Island. International Journal of Green Energy. 2014;12:570-6.

[10] Veigas M, Ramos V, Iglesias G. A wave farm for an island: Detailed effects on the nearshore wave climate. Energy. 2014;69:801-12.

[11] Veigas M, Carballo R, Iglesias G. Wave and offshore wind energy on an island. Energy for Sustainable Development. 2014;22:57-65.

[12] Fusco F, Nolan G, Ringwood JV. Variability reduction through optimal combination of wind/wave resources - An Irish case study. Energy. 2010;35:314-25.

[13] Lund H. Large-scale integration of optimal combinations of PV, wind and wave power into the electricity supply. Renewable Energy. 2006;31:503-15.

[14] Stoutenburg ED, Jenkins N, Jacobson MZ. Power output variations of co-located offshore wind turbines and wave energy converters in California. Renewable Energy. 2010;35:2781-91.

[15] Cradden L, Mouslim H, Duperray O, Ingram D. Joint exploitation of wave and offshore wind power. In: Proceedings of the nineth European wave and tidal energy conference (EWTEC). Southampton, UK2011. p. 1-10.

[16] Li W, Shen-Ron J, Chao-Nan L, Hao-Wen L, Yi-Hsuan H, Yi-Ting C, et al. Study of a hybrid offshore wind and seashore wave farm connected to a large power grid through a flywheel energy storage system. Power and Energy Society General Meeting, 2011 IEEE2011. p. 1-7.

[17] Li W, Shen-Ron J, Chao-Nan L, Hao-Wen L, Yi-Hsuan H, Yi-Ting C. Analysis of an integrated offshore wind farm and seashore wave farm fed to a power grid through a variable frequency transformer. Power and Energy Society General Meeting, 2011 IEEE2011. p. 1-7.

[18] Fernandez Chozas J, Helstrup Jensen NE, Sørensen HC. Economic benefit of combining wave and wind power productions in day-ahead electricity markets. In: Proceedings of the fourth international conference on ocean energy (ICOE). Dublin, Ireland2012.

[19] Fernandez Chozas J, Kofoed JP, Kramer MM, Sørensen HC. Combined production of a fullscale wave converter and a full-scale wind turbine - a real case study. In: Proceedings of the fourth international conference on ocean energy (ICOE). Dublin, Ireland2012. 
[20] Fernandez Chozas J, Kofoed JP, Sørensen HC. Predictability and Variability of Wave and Wind : wave and wind forecasting and diversified energy systems in the Danish North Sea. Aalborg University, Department of Civil Engineering, DCE Technical Reports; 2013.

[21] Babarit A. Estimation de la production dúne plateforme flottante hybride pour la recuperation de lénergie des vagues et du vent. In: Proceedings of the trezièmes journées de l'hydrodynamique. Chatou, France2012. p. 1-12.

[22] de Boer WW, Verheij FJ, Zwemmer LBV, R. Das GD. The energy island. An inverse pump accumulation station. In: Proceedings of the European wind energy conference. Milan, Italy: EWEA; 2007. p. 1-5.

[23] Perez C, Iglesias G. Integration of wave energy converters and offshore windmills. In: Proceedings of the fourth international conference on ocean energy (ICOE). Dublin, Ireland2012. p. $1-6$.

[24] Perez C, Iglesias G. Physical modelling of an offshore OWC wave energy converter mounted on a windmill monopile foundation. In: Troch P, Stratigaki V, De Roo S, editors. In: Proceedings of the international conference on the application of physical modelling to port and coastal protection (COASTLAB). Ghent, Belgium: Department of Civil Engineering, Ghent University; 2012. p. 1-10.

[25] Quevedo E, Delory M, Castro A, Llinas O, Hernandez J. Modular multi-purpose offshore platforms, the TROPOS project approach. In: Proceedings of the fourth international conference on ocean energy (ICOE). Dublin, Ireland2012. p. 1-5.

[26] Quevedo E, Delory M, Castro A, Llinas O, de Lara J, Papandroulakis N, et al. Multi-use offshore platform configurations in the scope of the FP7 TROPOS Project. In: Proceedings of the OCEANS MTS/IEE Conference. Bergen, Norway2013. p. 1-7.

[27] Perez-Collazo C, Jakobsen MM, Buckland H, Fernandez Chozas J. Synergies for a wave-wind energy concept. In: Proceedings of the European offshore wind energy conference. Frankfurt, Germany: EWEA; 2013. p. 1-10.

[28] MARINA Platform. MARINA Platform web page. EU FP7 Co-ordinated Action Project "Marine Renewable Integrated Application Platform - MARINA Platform"; 2014.

[29] ORECCA. ORECCA web page. EU FP7 Co-ordinated Action Project "Offshore Renewable Energy Conversion - ORECCA"; 2012.

[30] TROPOS. TROPOS web page. EU FP7 Co-ordinated Action Project "Modular multi-use Deep Water Offshore Platform Harnessing and Servicing Mediterranean, Subtropical and Tropical Marine and Maritime Resources - TROPOS"; 2013.

[31] H2OCEAN. H2OCEAN web page. EU FP7 Co-ordinated Action Project "H2OCEAN"; 2014.

[32] MERMAID. MERMAID web page. EU FP7 Co-ordinated Action Project "Innovative Multipurpose offshore platforms: planning, design and operation - MERMAID"; 2014.

[33] Casale C, Serri L, Stolk N, Yildiz I, M. C. Synergies, innovative designs and concepts for multipurpose use of conversion platforms. Results of ORECCA Project - WP4. 2012. p. 1-77. 
[34] Serri L, Sempreviva AM, Pontes T, Murphy J, Lynch K, Airoldi D, et al. ORECA. Resource Data and GIS Tool. For Offshore Renewable Energy Projects in Europe. EU FP7 Co-ordinated Action Project "Offshore Renewable Energy Conversion - ORECA"; 2012. p. 1-104.

[35] Murphy J, Lynch K, O'Sullivan K. Deliverable D3.3. Methodologies for analysis and assessment of wind-ocean combined concepts. 2012. p. 1-48.

[36] Wave Star AS. Wave Star Energy web page. Wave Star AS; 2012.

[37] Power-technology.com. Green Ocean Energy Wave Trader web page. Net Resources International - NIR; 2010.

[38] Royal Belgiam Institute of Natural Sciences. NORTH SEA FACTS web page. Management Unit of North Sea Mathematical Modelss; 2012.

[39] European Commission. COMMUNICATION FROM THE COMMISSION TO THE EUROPEAN PARLIAMENT, THE COUNCIL, THE EUROPEAN ECONOMIC AND SOCIAL COMMITTEE AND THE COMMITTEE OF THE REGIONS: Blue Growth - opportunities for marine and maritime sustainable growth. Brussels, Belgium: European Commission; 2012. p. 1-12.

[40] European Commission. COMMUNICATION FROM THE COMMISSION TO THE EUROPEAN PARLIAMENT, THE COUNCIL, THE EUROPEAN ECONOMIC AND SOCIAL COMMITTEE AND THE COMMITTEE OF THE REGIONS: Blue Energy Action needed to deliver on the potential of ocean energy in European seas and oceans by 2020 and beyond. Brussels, Belgium: European Commission; 2014. p. 1-11.

[41] Britain G. Energy Act 2004. Stationery Office; 2004.

[42] Britain G. Climate Change Act 2008. Stationery Office; 2008.

[43] European Commission. Proposal for a DIRECTIVE OF THE EUROPEAN PARLIAMENT AND OF THE COUNCIL establishing a framework for maritime spatial planning and integrated coastal management. Brussels, Belgium: European Commission; 2013. p. 1-35.

[44] Greaves D, Pérez Collazo C, Magagna D, Conley D, Bailey I, Simas T, et al. Enabling Wave Power: Streamlining processes for progress. Plymouth, UK2013. p. 1-34.

[45] SOWFIA. SOWFIA web page. IEE project "Streamlining of Ocean Wave Farms Impact Assessment - SOWFIA"; 2013.

[46] Musial W, Ram B. Large-Scale Offshore Wind Power in the United States: Assessment of Oppportunities and Barriers. Golden, US: National Renewable Energy Laboratory; 2010. p. 1-221.

[47] Carballo R, Iglesias G. Wave farm impact based on realistic wave-WEC interaction. Energy. 2013;51:216-29.

[48] Abanades J, Greaves D, Iglesias G. Wave farm impact on the beach profile: A case study. Coastal Engineering. 2014;86:36-44.

[49] Renewable Energy Focus. Gravitational wave energy absorber presented. Renewable Energy Focus: Elsevier Ltd.; 2010. 
[50] Pelagic Power AS. W2Power web page. 2010.

[51] OWWE Ltd. Ocean Wave and Wind Energy web page.

[52] Floating Power Plant AS. Poseidon Floating Power web page. 2013.

[53] Principle Power Inc. WindFloat web page. 2011.

[54] Float Inc. Offshore Ocean Energy System web page. 2011.

[55] Energy Island Ltd. Energy island web page. 2009.

[56] Kaiser MJ, Snyder BF. Offshore Wind Energy Cost Modeling: Installation and Decommissioning. London: Springer; 2012.

[57] Fichaux N, Wilkes J. Oceans of Opportunity. Harnessing Europe's largest domestic energy resource. Brussels, Belgium: European Wind Energy Association; 2009. p. 1-69.

[58] Arapogianni A, Moccia J, Williams D, Phillips J. Wind in our Sails. European Wind Energy Asociation; 2011. p. 1-93.

[59] 4C Offshore. Global Offshore Wind Farms Database web page. 2012.

[60] LORC. LORC - Lindoe Offshore Renewables Ceter test and demonstrates technology for harnessing renewable energy offshore wave page. 2011.

[61] Byrne BW, Houlsby GT. Foundations for offshore wind turbines. Philosophical Transactions of the Royal Society of London Series A: Mathematical, Physical and Engineering Sciences.

2003;361:2909-30.

[62] Henderson AR, Morgan C, Smith B, Sørensen HC, Barthelmie RJ, Boesmans B. Offshore Wind Energy in Europe- A Review of the State-of-the-Art. Wind Energy. 2003;6:35-52.

[63] Burton T, Jenkins N, Sharpe D, Bossanyi E. Wind energy handbook. Chichester, UK: Wiley; 2011.

[64] Arapogianni A. The European offshore wind industry - key trends and statistics 2012. In: Association EWE, editor. Brussels: EWEA; 2013. p. 1-31.

[65] Thomsen JH, Forsberg T, Bittner R. Offshore wind turbine foundations-the COWI experience. In: Proceedings of the ASME twuenty-sixth international conference on offshore mechanics and arctic engineering (OMAE)2007.

[66] Nikolaou N. Deep water offshore wind technologies [Master in Science]. Glasgow: University of Strathclyde; 2004.

[67] Lozano-Minguez E, Kolios AJ, Brennan FP. Multi-criteria assessment of offshore wind turbine support structures. Renewable Energy. 2011;36:2831-7.

[68] Ibsen LB. The bucket foundation and its competitiveness versus monopiles and jacket structures. In: Proceedings of the internatrional conference in research at Alpha Ventus (RAVE). Bremerhaven, Germany: Fraunhofer IWES; 2012. 
[69] de Vires WE. Assessment of bottom-mounted support structure types with conventional design stiffness and installation techniques for typical deep water sites. Uwpind WP4: Offshore foundations and support structures2007. p. 1-76.

[70] UpWind. UpWind. Finding design solutions for very large wind turbines web page. EU FP6 Coordinated Action Project "Integrated Wind Turbine Design - UpWind"; 2011.

[71] EWEA. The European offshore wind industry key 2011 trends and statistics. EWEA; 2012.

[72] Alpha ventus. Alpha ventus web page. Alpha ventus; 2013.

[73] Dong W, Moan T, Gao Z. Long-term fatigue analysis of multi-planar tubular joints for jackettype offshore wind turbine in time domain. Engineering Structures. 2011;33:2002-14.

[74] Seidel M. Jacket substructures for the REpower 5M wind turbine. In: Proceedings of the European offshore wind energy conference. Berlin, Germany2007.

[75] BARD Holding GmbH. BARD web page. BARD holding GmbH; 2012.

[76] Stahlmann A, Schlurmann T. Physical modelling of scour around tripod foundation structures for offshore wind energy converters. In: Proceedings of the international conference on coastal engineering (ICCE). Shanghai, China2011.

[77] Statoil. Hywind - the world's fist full-scale floating wind turbine web page. Statoil; 2009.

[78] SWAY AS. SWAY. Changing the future of the wind Power web page. SWAY AS; 2012.

[79] Sclavounos PD, Lee S, DiPietro J, Potenza G, Caramuscio P, De Michele G. Floating offshore wind turbines: tension leg platform and taught leg buoy concepts supporting 3-5 mw wind turbines. In: Proceedings of the European wind energy conference. Warsaw, Poland2010.

[80] Blue H. Blue H. Floating platform technology for offshore wind energy web page. Blue H Technologies BV,; 2013.

[81] Roddier D, Cermelli C, Aubault A, Weinstein A. WindFloat: A floating foundation for offshore wind turbines. Journal of renewable and sustainable energy. 2010;2:033104-34.

[82] Carballo R, Iglesias G. A methodology to determine the power performance of wave energy converters at a particular coastal location. Energy Conversion and Management. 2012;61:8-18.

[83] Drew B, Plummer AR, Sahinkaya MN. A review of wave energy converter technology. Journal of power and energy. 2009;223:887-902.

[84] McCormick ME. Ocean Wave Energy Conversion. New York: Dover ed.; 1981.

[85] Clément A, McCullen P, Falcão AFdO, Fiorentino A, Gardner F, Hammarlund K, et al. Wave energy in Europe: current status and perspectives. Renewable and Sustainable Energy Reviews. 2002;6:405-31.

[86] Thorpe TW. A brief review of wave energy. In: industry TUDoTa, editor. London, UK: Hardwell Laboratory, Energy Technology Support Unit; 1999. p. 1-140. 
[87] Falnes J. A review of wave-energy extraction. Marine structures. 2007;20:185-201.

[88] Iglesias G, Carballo R. Effects of high winds on the circulation of the using a mixed open boundary condition: the Ría de Muros, Spain. Environmental Modelling \& Software. 2010;25:45566.

[89] Falcão AFdO. Wave energy utilization: A review of the technologies. Renewable and Sustainable Energy Reviews. 2010;14:899-918.

[90] López I, Iglesias G. Efficiency of OWC wave energy converters: A virtual laboratory. Applied Ocean Research. 2014;44:63-70.

[91] Brito-Melo A, Gato LMC, Sarmento AJNA. Analysis of Wells turbine design parameters by numerical simulation of the OWC performance. Ocean Engineering. 2002;29:1463-77.

[92] Ente Vasco de la Energía. EVE web page. 2014.

[93] Pelamis Wave Power. Pelamis Wave Power web page. 2014.

[94] Ocean Power Technologies Inc. OPT web page. 2014.

[95] Fernandez H, Iglesias G, Carballo R, Castro A, Fraguela JA, Taveira-Pinto F, et al. The new wave energy converter WaveCat: Concept and laboratory tests. Marine structures. 2012;29:58-70.

[96] Tedd J, Kofoed JP. Measurements of overtopping flow time series on the Wave Dragon, wave energy converter. Renewable Energy. 2009;34:711-7.

[97] Kofoed JP, Frigaard P, Friis-Madsen E, Sørensen HC. Prototype testing of the wave energy converter wave dragon. Renewable Energy. 2006;31:181-9.

[98] Wave Dragon AS. Wave Dragon web page. 2005.

[99] COAST Research Group. Coastal, Ocean and Sediment Transport Research Group (COAST) web page. 2014.

[100] Iglesias G, Fernández H, Carballo R, Castro A, Taveira-Pinto F. The WaveCat@-Development of a new wave energy converter. In: Proceedings of the world renewable energy congress (WREC). Linköping, Sweden2011. p. 2151-8.

[101] Bazilevs Y, Hsu MC, Akkerman I, Wright S, Takizawa K, Henicke B, et al. 3D simulation of wind turbine rotors at full scale. Part I: Geometry modeling and aerodynamics. International journal for numerical methods in fluids. 2011;65:207-35.

[102] Li Y, Yu Y. A synthesis of numerical methods for modeling wave energy converter-point absorbers. Renewable and Sustainable Energy Reviews. 2012;16:4352-64.

[103] HMRC, Marine Institute of Ireland. OCEAN ENERGY: Development \& Evaluation Protocol. Part 1: Wave Power. Hydraulics Marine Research Centre; 2003. p. 1-32.

[104] Holmes B. Tank testing of wave energy conversion systems. In: EMEC, editor. Marine renewable energy guides. London: The European marine energy centre (EMEC); 2009. p. 1-82. 